\title{
Staging Impermanence: Material Theatres
}

\author{
by
}

Rachel Irving-Beer

A thesis submitted to the Faculty of Graduate and Postdoctoral Affairs in partial fulfillment of the requirements for the degree of

Master of Architecture

in

M.Arch (Professional)

Carleton University

Ottawa, Ontario

(C) 2019

Rachel Irving-Beer 



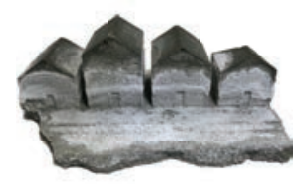

ABSTRACT

PROLOGUE: LA RAISON D'ÊTRE

IMPOSSIBLE BY HAND

INTRODUCTION

BEYOND BIOMIMICRY

RESEARCH AND EXPERIMENTATION

Preface to Proposed Design

PART 1: EXPERIMENTAL ARCHITECTURE
NEPEAN POINT
MUTABLE AND IMMUTABLE
SITE AS STORY-TELLER
MATERIAL AS STORY-TELLER
INTERVENTION

PART 2: MATERIAL THEATRES

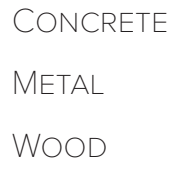

PART 3: A THEATRE IN TIME

$$
\begin{aligned}
& \text { MOdel 1: THE OPENING NIGHT } \\
& \text { MOdel 2: THE FALLING ACtION } \\
& \text { MOdel 3: THE FINAL CURTAIN } \\
& \text { MOdel 4: THE ENCORE }
\end{aligned}
$$

POSTSCRIPT

BIBLIOGRAPHY 


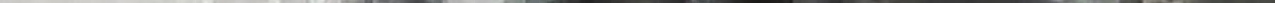




\section{ABSTRACT}

Evolving materials are inherent in nature: we are used to seeing but also remaining blind to growth in materials such as trees, corals, sand dunes. There are erosion patterns, crystallization, vitrification and fossilization. Less common, however, is to see such evolving materials in the realm of the built environment. While we take advantage of self-formed natural materials like trees and rocks, the process of building involves arresting the material's evolutionary/devolutionary process. A central conceit of architecture is that buildings, once constructed, remain static. If a building changes post-construction, it is usually considered undesirable. Architects go to considerable lengths to avoid accretions like mould or mildew, or detractions such as crumbling or decay. This thesis systematically explores the stresses created in selected materials, their performance under various external catalysts, and any resulting emerging characteristics. Through a series of rigorous material experiments, the purpose of this thesis is to explore what can happen when building materials are not just allowed but encouraged to follow their inherent tectonic forces, and how the process

of degeneration might be integrated into the constructed and constructive form. The resulting project will involve the brief of a displaced theatre, which has to vacate for two years from its premises for purposes of renovation and upgrade. A temporary theatre, hovering between permanence and impermanence, sited on a precarious cliff, is proposed to dissolve in material and structure over the years and become the setting of the various interim productions. 


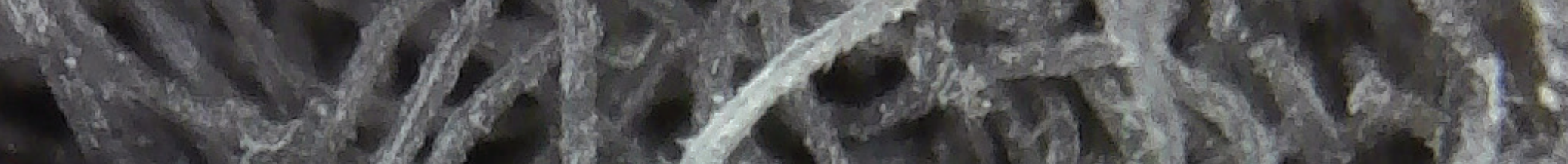
$4 \sin 30$ 


\section{PROLOgue: LA RAISON D'ÊTRE}

"The correlation between Architecture and permanence is predominantly a western concept. Hindu, Taoist and Buddhist philosophy embrace the impermanence of all things in the universe, including buildings, and believe that they should be allowed to die too. Sub-Saharan Africa's traditional pastoral societies believe that buildings are not meant to outlast their owners, and as a result use biodegradable and renewable local materials that embody the idea of sufficiency. These buildings leave only their foundation's footprint when their time comes." (DuPlessis and Edwards 2001)
From my work as a cabinet-maker, I have a deep appreciation for the beauty in precision construction; but there is also something enchanting in construction that can never be exactly replicated, construction that can only exist once in an exact iteration and may change (evolve, grow, decay, disappear) at any time.

To contextualize this it would be appropriate to bring attention to the Japanese concept called Wabi Sabi, described by Andrew Juniper in Wabi Sabi: The Japanese Art of Impermanence (Juniper 2003) as "an intuitive appreciation of a transient beauty in the physical world that reflects the irreversible flow of life in the spiritual world....an understated beauty that exists in the modest, rustic, imperfect, or even decayed, an aesthetic sensibility that finds a melancholic beauty in the impermanence of all things."

As the objects we construct age and decay, they are invariably cast aside in favour of the shiny and the new-our built objects are piling up in droves all across the globe. But what would happen if, instead of casting things aside, we started designing and building to make aging a desirable outcome? Not just as a static target, but to privilege the entire process, from conception to disintegration?
LEFT: Dust bunny found at Carleton School of Architecture and Urbanism (photo by author) 


\section{IMPOSSIBLE BY HAND}

As materials change and evolve over time, the emergent structures, patterns, and formations would all be impossible to reproduce by hand. This reality plays out at several different levels: The object that would be impossible to produce without the aid of tools-hammer, nails, saw; the object that would be impossible to produce without the aid of modern tools-power saw, band saw, drill; the object that would be impossible to create without the aid of rapid prototyping tools-CAD, CNC, 3D printer; and the object that, even with the aid of all the tools available, is simply impossible to precisely reproduce.

Just as the best scientists of our time are unable to understand the workings of the human brain in its entirety-much less replicate it-the same is true to an even greater extent for the natural world. Even with new algorithmic design and rapid prototyping techniques, fabrication still has its limits. In order to produce something using rapid prototyping methods, it needs to be modeled accurately on the computer. Therein lies one of our first issues: computer code is deterministic, whereas natural formations are heuristic.

To model natural formations created from, for example, the exact pattern of peeling paint on the surface of a piece of steel as it rusts would require an absurd number of variables to be input and controlled; the exact manufacturing process, the precise crystalline makeup of the metal, every single element that comes into contact with the surface over the course of its life in exact exposure proportion, the precise makeup of the paint, how
HEURISTIC:

Proceeding to a solution by trial and error or by rules that are only loosely defined. The results are never quite the same, but the general boundaries are constant. In computer science, a heuristic (from Greek "I find, discover") is a technique designed for solving a problem more quickly when classic methods are too slow, or for finding an approximate solution when classic methods fail to find any exact solution. 
DETERMINISTIC:

A deterministic algorithm is an algorithm which, given a particular input, will always produce the same output, with the underlying machine always passing through the same sequence of states.

RIGHT: (Juniper 2003) it was applied, precise weather patterns since application, etc. This kind of exactitude may one day be possible with coding and computers, but at present, it remains a practical impossibility.

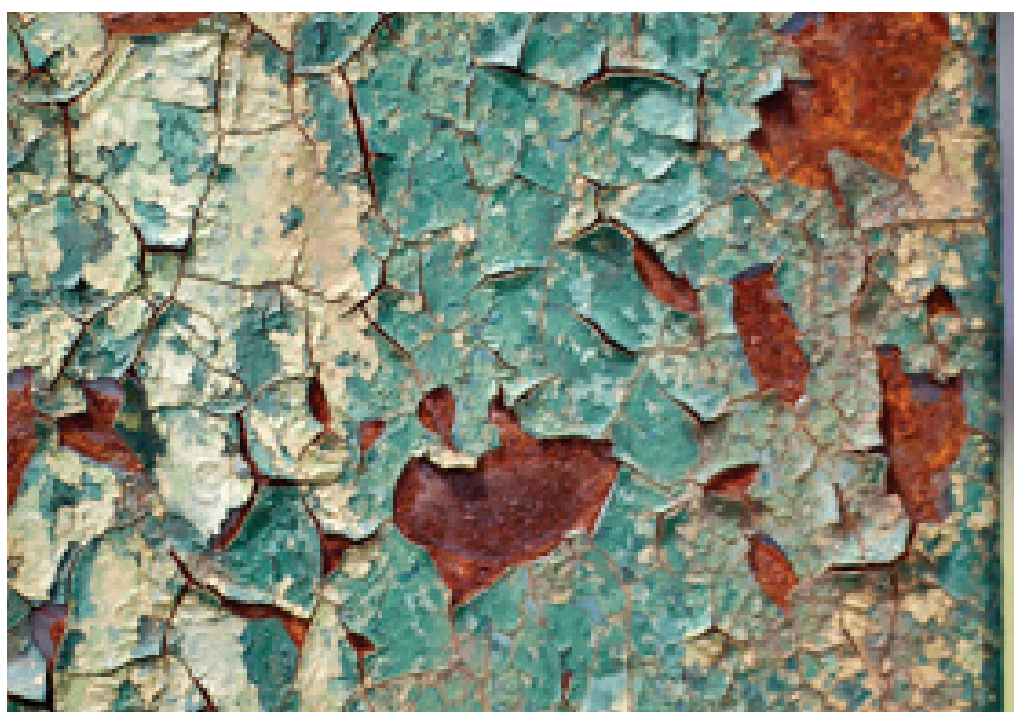

Whilst impossible to recreate this sort of exact simulation using known techniques, one way in which it may be possible to approximate natural formations is by using computer algorithms and mathematical formulae. However, even the issue of programming inputs becomes problematic when we realize that the truly random numbers of the sort required to simulate a multitude of variables are a practical impossibility even for computers today. 
As Steven Skiena, in The Algorithm Design Manual put it,

"unfortunately, generating random numbers looks a lot easier than it really is. Indeed, it is fundamentally impossible to produce truly random numbers on any deterministic device. Von Neumann [Neu63] said it best: "Anyone who considers arithmetical methods of producing random digits is, of course, in a state of sin." The best we can hope for are pseudo-random numbers, a stream of numbers that appear as if they were generated randomly."

(Skiena 2008)

While computer simulation is useful for modeling artificial systems, it has not yet been developed to the point where it can faithfully reproduce "true" randomness as expressed in natural processes. Computer modeling is an inherently deterministic process, based on static algorithms, and cannot create the inherent randomness of heuristic outcomes.

It is not as though this disconnect has lacked attention from some of the world's greatest thinkers. Many scientists and academics, such as Albert Einstein and Stephen Hawking, have devoted considerable time and effort to the question of a "theory of everything" that would wash away many uncertainties about the nature of life and the universe, including the practical impossibility previously identified. (And if that effort has been anything at all, it has certainly been impossible by hand.)

Tantalizing a pursuit as it is, it is not at all clear that a "theory of everything" is attainable. But until such a theory is established-if it ever can be-it is certainly conceivable that a "theory of everything" would stand alongside the current mystery that is our understanding of the world, as opposed to simply incorporating it. 
Adre re

$\cos ^{2}$

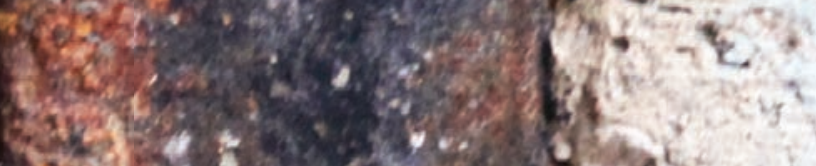

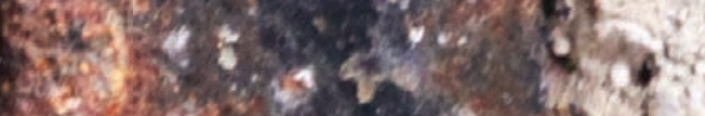

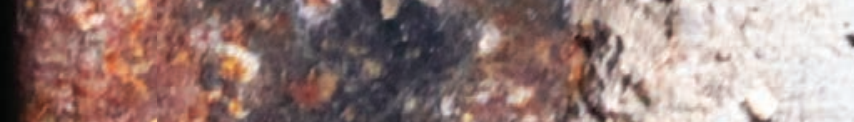

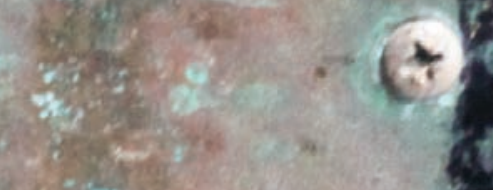

$\log ^{2}$

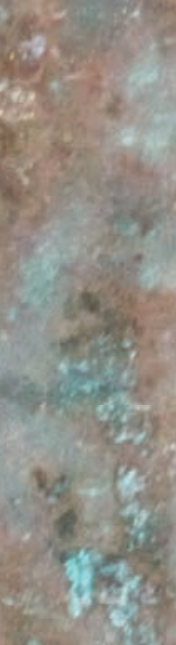

tare

3.

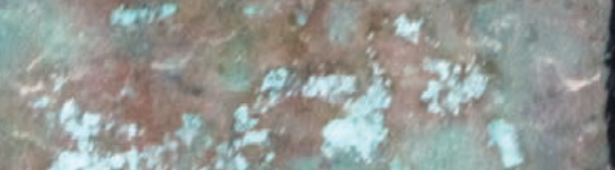

to

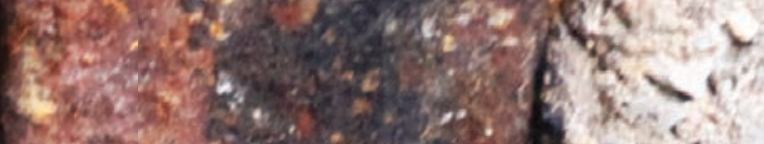

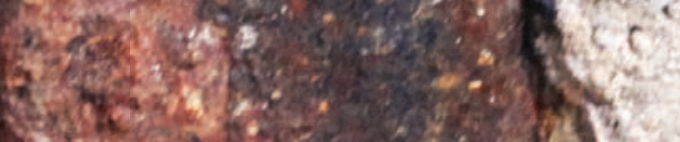

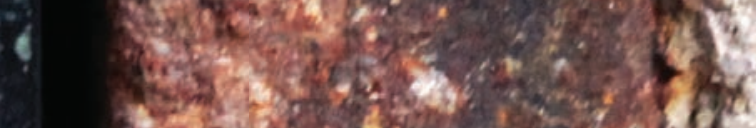

t.

1
3
3

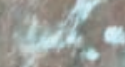

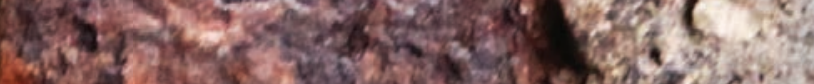

(1)

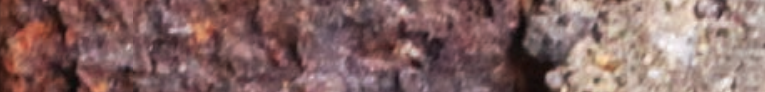

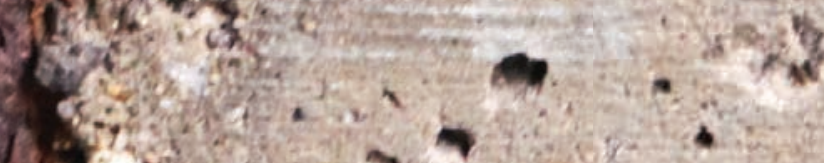

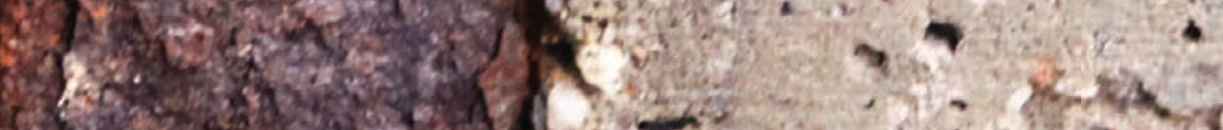

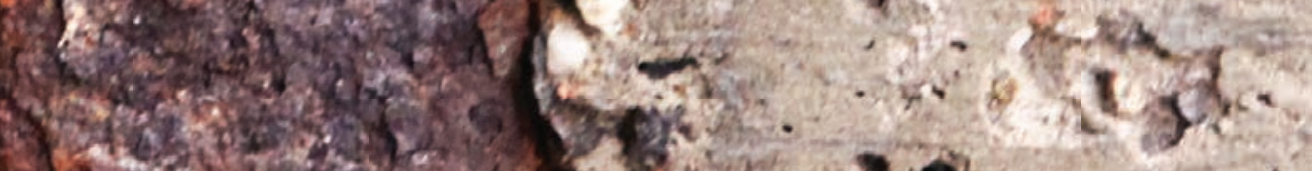

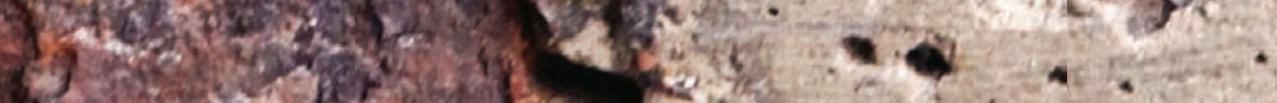

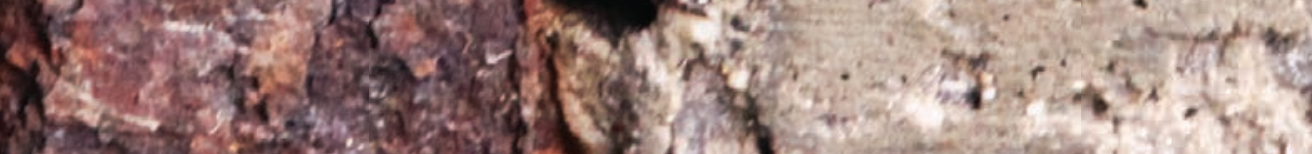

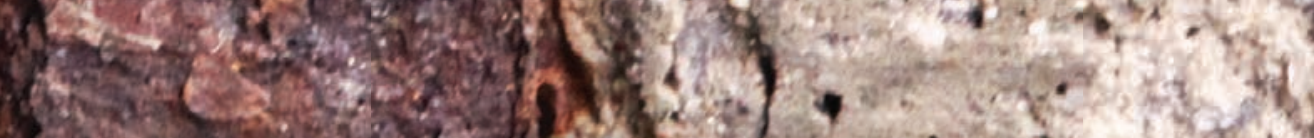
W.

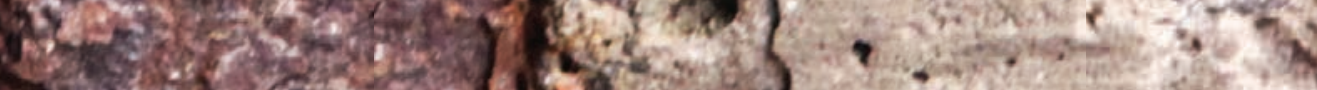

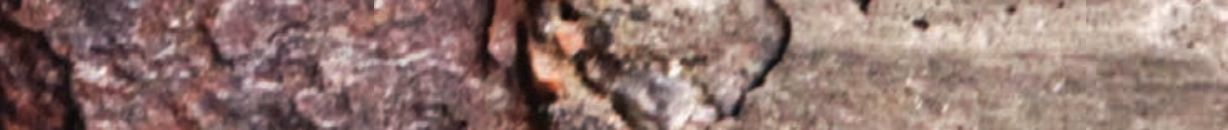
(3) 


\section{INTRODUCTION}

"The notion that someday nature could swallow whole something so colossal and concrete as a modern city doesn't slide easily into our imaginations. The sheer titanic presence of New York City resists efforts to picture it wasting away... Nevertheless, the time it would take nature to rid itself of what urbanity has wrought may be less time than we suspect."

\section{-The World Without Us, Alan Weisman}

What happens to buildings as they age? How can the discourse on aging materials be shifted from something we design to prevent-sealing wood, UV coating, galvanizing, etc.-into something we design to encourage and privilege?

In order to change that discourse, we need to know what we're dealing with. We need to know how things change over time, what causes each different reaction, and why that reaction could be an interesting development rather than of being considered negative.

We already employ mild forms of material decay in architecture: weathering steel for example-more commonly known under the trademark COR-TEN steel. This material is defined by a group of steel alloys that are designed to form a patina of rust on the surface over the course of several years, but still remain structurally viable. Precautions are made to keep the steel from rusting too much though-when building with this material, efforts are made to prevent water collecting on the surface, drainage pockets are still 
installed, and the rusty runoff still needs to be managed carefully to prevent

"bleeding" onto the surrounding materials.

But while the concept is not unknown, its potential scope has not been explored to the extreme. A guiding intent for this research is to do exactly that: to extend a provocative idea as far as it can imaginably go, almost certainly beyond the point of practical application, listen carefully to what that process of imagining can tell us, then distill it down to more practical thinking-and, conceivably, to a practical application.

\section{BEYOND BIOMIMICRY}

Biomimicry has been a useful and increasingly mainstream concept ever since natural science writer Janine Benyus introduced it in the late 1990s. While she may not have coined the term biomimicry, she certainly popularized it in her book Biomimicry: Innovation Inspired by Nature.

Though biomimicry has an astonishing array of practical applications, this research is about more than just mimicry. The purpose of this body of work is to understand how to harness natural processes, rather than simply seeking to imitate them.

In his paper Biomimetics: its practice and theory, Julian Vincent writes that biomimicry is "a relatively young study embracing the practical use of mechanisms and functions of biological science in engineering, design, chemistry, electronics, and so on. However, people have looked to nature for inspiration for more than 3,000 years (since the Chinese first tried to make an artificial silk)." (Vincent, et al. 2006)

Rather than studying the properties of biological processes and attempting to invent a new technology to imitate them, leading edge thinkers in architecture and design are giving serious consideration to methods of harnessing the already occurring processes and incorporating them more thoroughly into the built environment. Some examples of this include:
"Even if you live in a denatured, postmodern subdivision where heavy machines mashed the landscape into submission, replacing unruly native flora with obedient sod and uniform saplings, and paving wetlands in the righteous name of mosquito controleven then, you know that nature [isn't] fazed." -The World Without Us, Alan Weisman

BIOMIMICRY: The design and production of materials, structures, and systems that are modeled on biological entities and processes. (Oxford Dictionary)

"This (style of design) contrasts markedly with the design approach that characterized the 20th century: the mechanization of functions in order to overpower, isolate, and control forces of nature, usually by utilizing advances in chemistry and physics."-BioDesign, MoMa

"Designers face an unprecedented urgency to alter their methods and reprioritize their goals to address the accelerating degradation of the environment" -BioDesign, MoMa 
IMAGE: (BlingCrete 2018)

IMAGE: (Ecovative Design 2011)

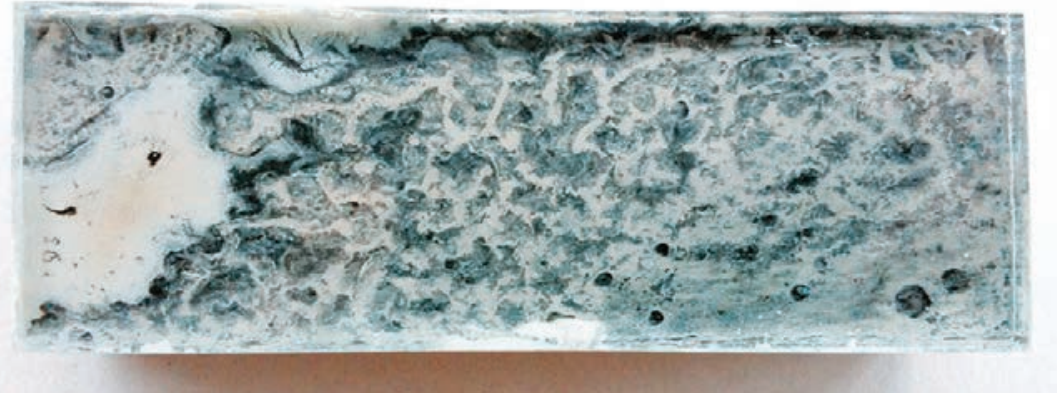

From Berlin company Bling Crete: "DysCrete is a dye-sensitized energy-generating concrete made by coating prefabricated concrete components with layers of organic dyes held in suspension. Dye-sensitized solar cells (DYSCs) rely on a photoelectrochemical process to convert light into energy. Made of light-reactive natural dyes from substances like spinach chlorophyll, the cells generate power that is harnessed by oxide electrodes. This technology has the advantages of low cost and flexible applicability, but its long-term stability is a challenge to optimize."

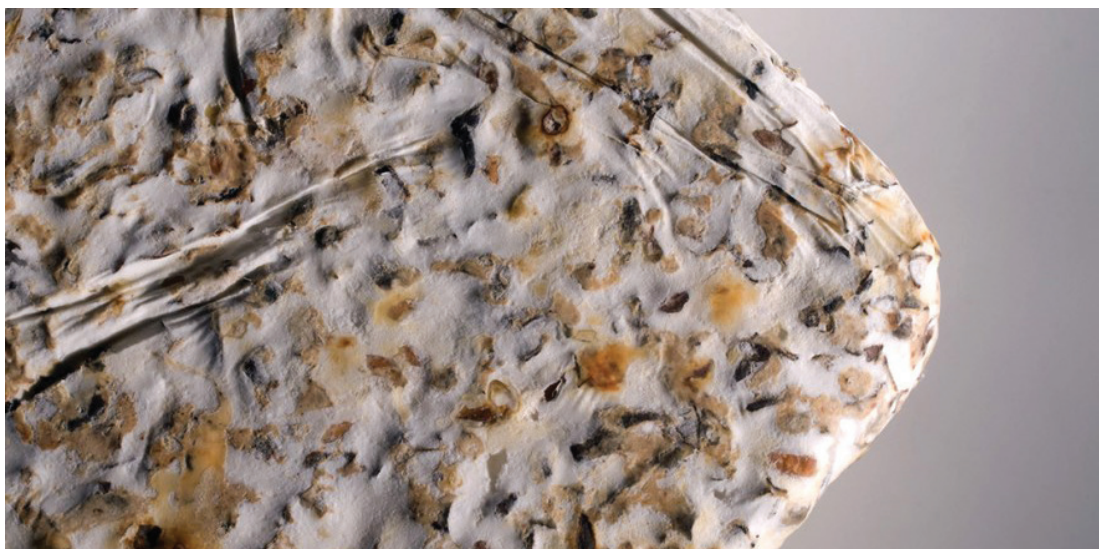

From NY company Ecovative Design: "Mycobond is a mycological biocomposite that can be used in a wide variety of applications. Instead of conventional manufacturing processes, Mycobond uses myceliumwhich is essentially the root system of a mushroom-to transform loose aggregates into strong composites. This process can be varied by using different species of fungus and mixtures of aggregates in order to make a composite with an optimal density, strength, appearance, and performance for the specific application." 


\section{$12=.32$}

sin if है

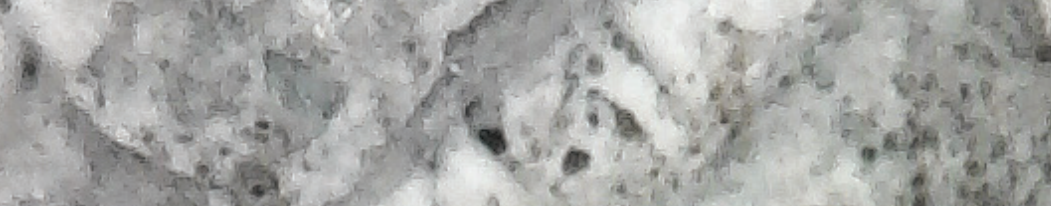

and $n$

2)

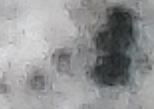

a.t.

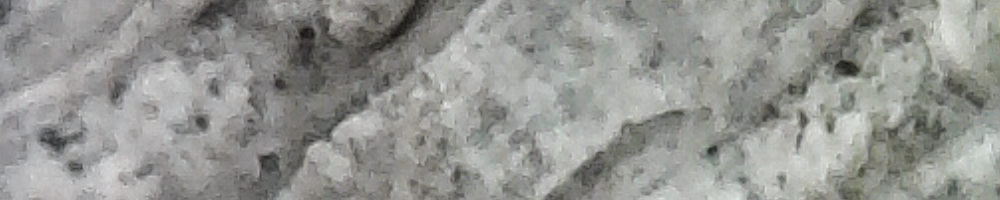

$-i$

1

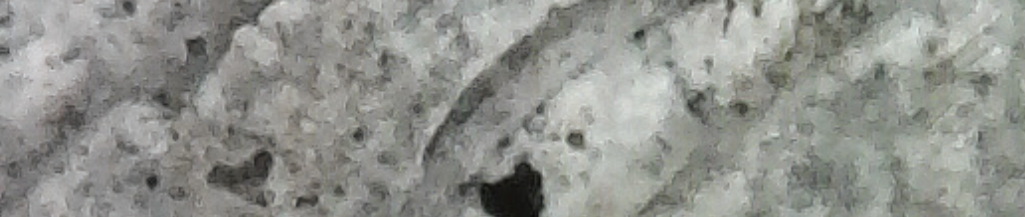

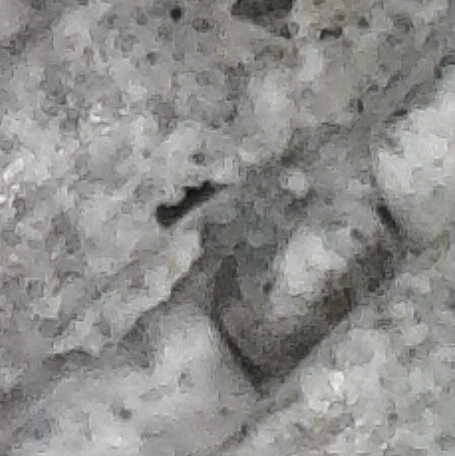

7

s.

- 3.00

ise $x^{2}$

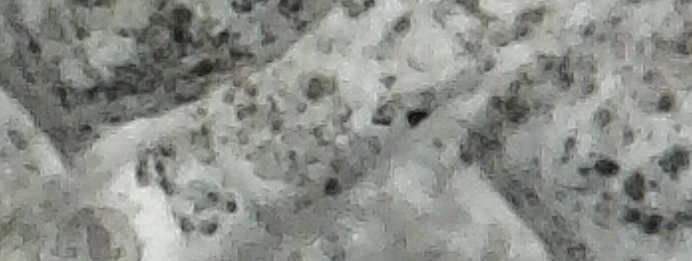

c.

Af $x^{2} a^{2}$

$\lim ^{4} x^{3}$

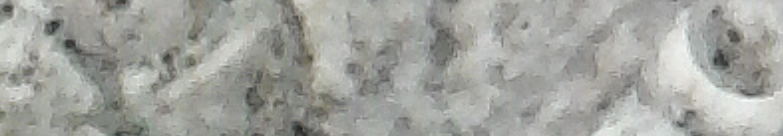

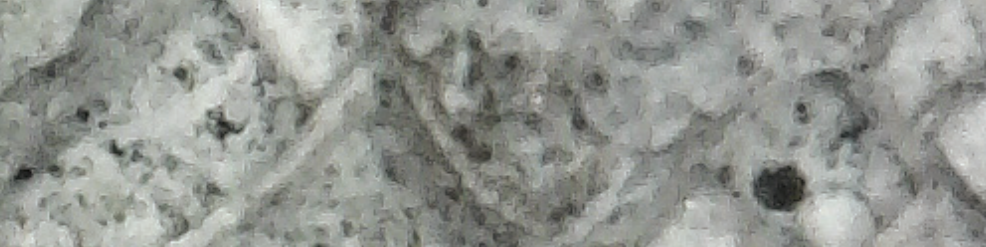

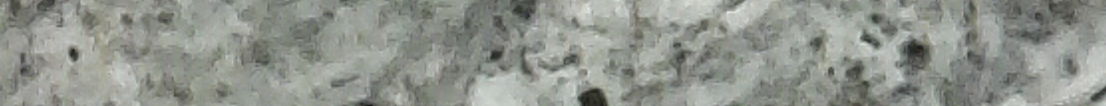

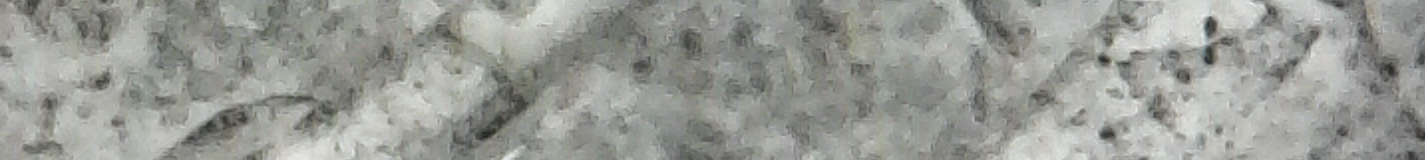

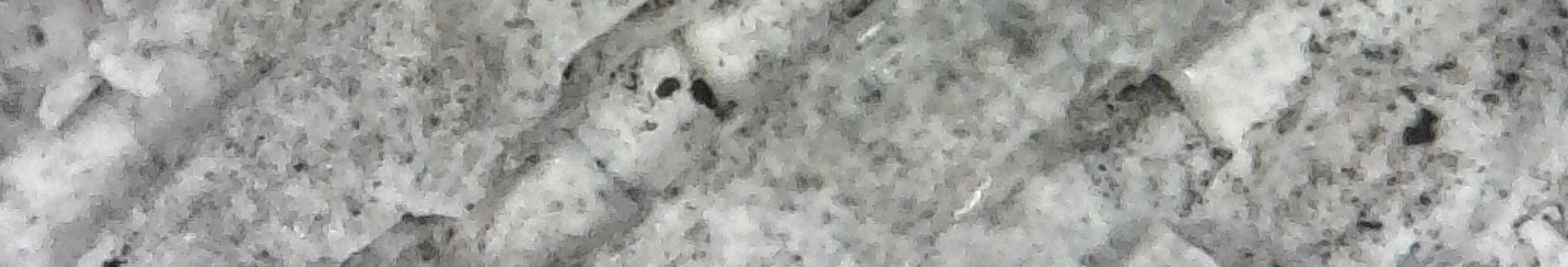

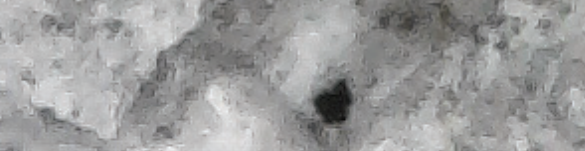
a
$-30$

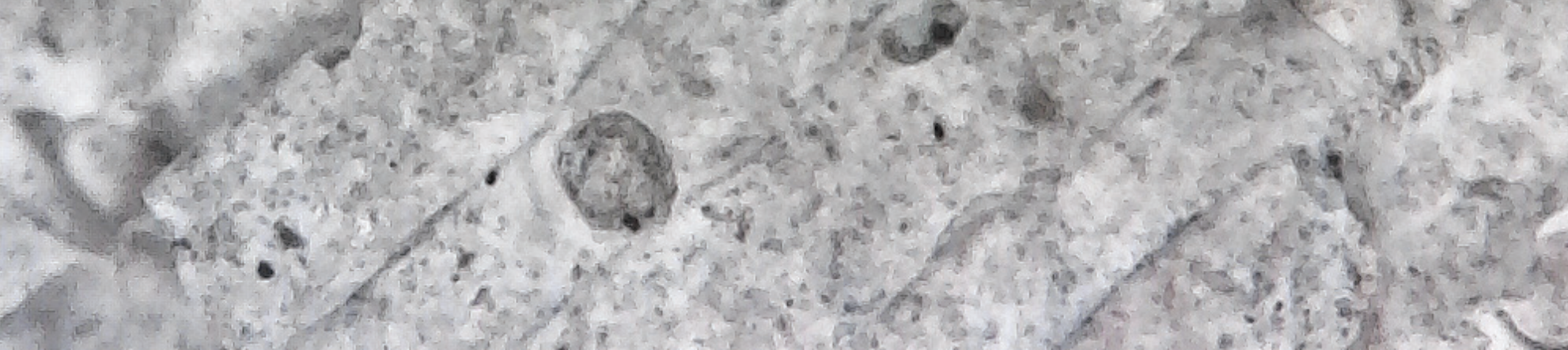

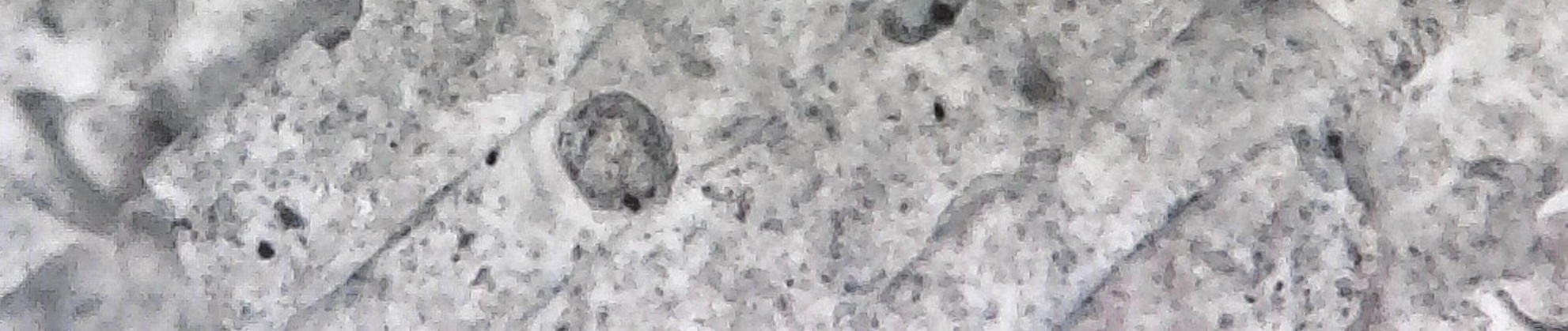




\section{RESEARCH AND EXPERIMENTATION}

"Ideas are not based on principles of rigid hierarchy but on an intense exploration of the immediate... When we attempt to trap chaos and convert it to our preconceptions, Order! becomes an enormous effort. We try to eliminate fault or error. We try hard but the effort turns to dullness and the heavy formal."

\section{-Cecil Belmond, Informal}

According to Fundamentals of Building Construction, by Edward Allen and Joseph lano, the most common building materials used in new constriction in Canada are concrete, timber, and steel, the three categories of materials used here. As these are the three most common building materials in new construction, the resultant decay on, around, and because of these materials would be the most prevalent. Indeed one only needs to take a short walk through the Carleton Azrieli School of Architecture building to spot prime examples of all of these.

Salt from the boots of thousands of students over the years has seeped

LEFT: microscopic image captured of efflorescence experiment (photo by author)

RIGHT: Rotting wood on the wall of the pit (photo by author)

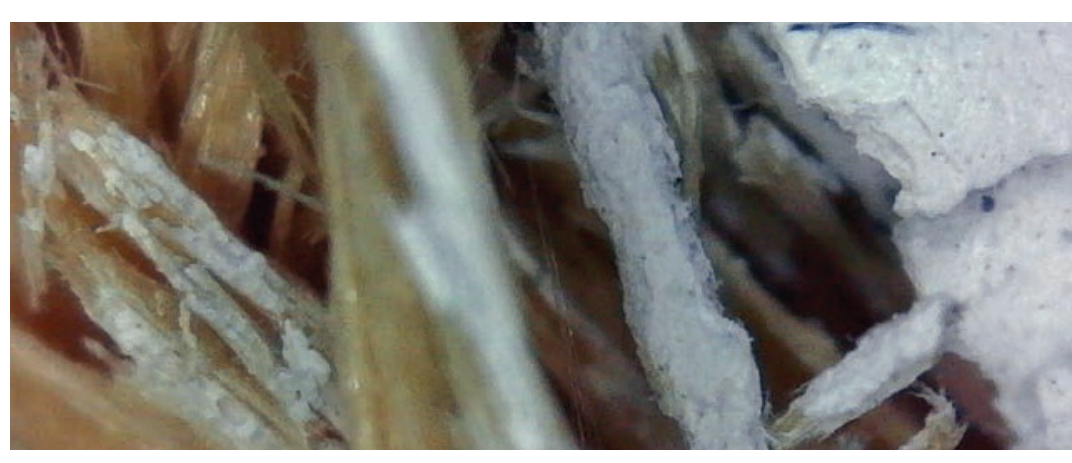




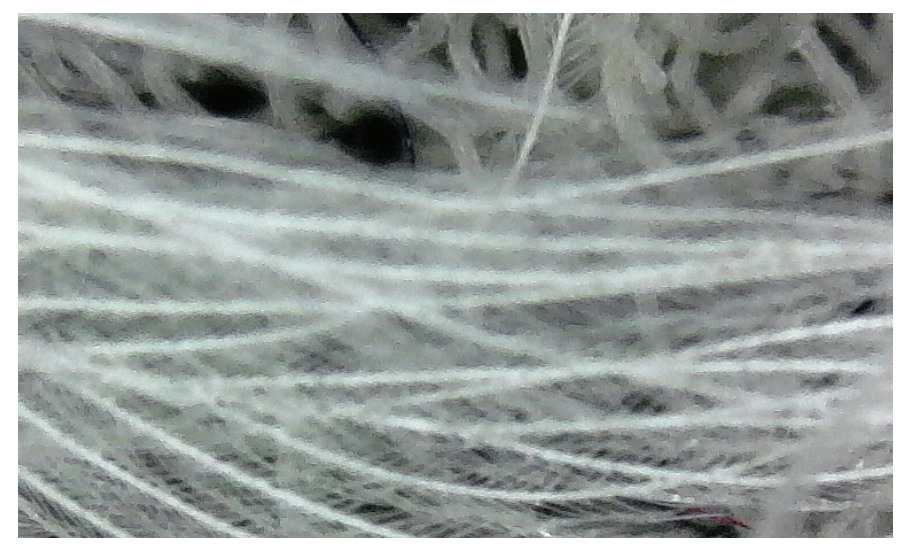

Microscopic

photos of

detritus and

decay found

in the Carleton

University Pit:

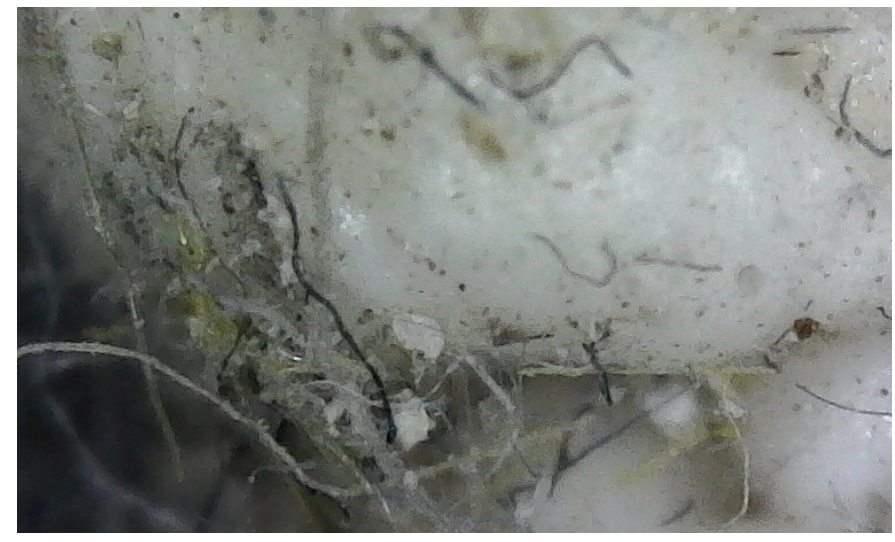

Carpet dirt

Gum stuck to

concrete

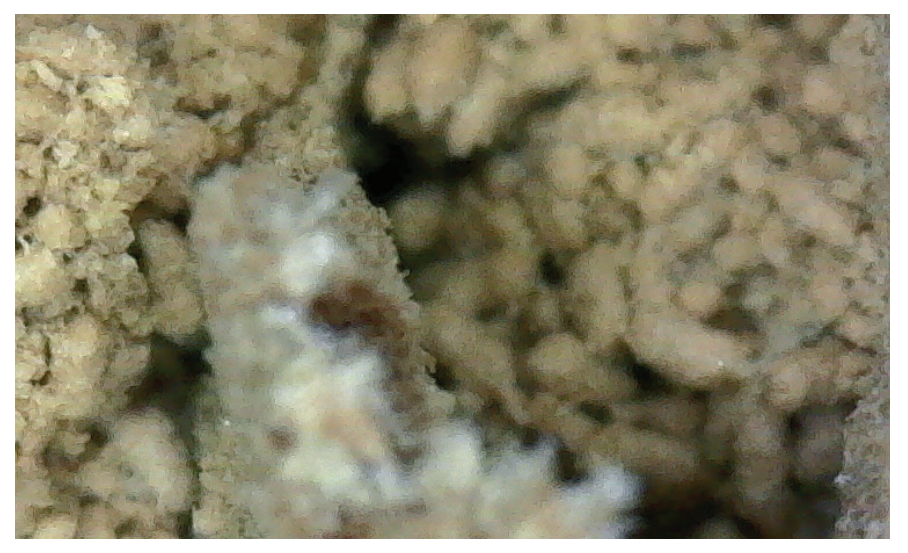

Decaying wood

into the concrete floors and walls of the school, wicking up and evaporating as time passes, forming white stains. Rust from oxidized rebar and framing leeches out at every joint, dried and crackling, developing more with each passing semester. The wooden steps lining the Pit space in the school have been replaced recently, but even they are starting to show signs of wear-the varnish that seals them from the elements is starting to flake and crack, allowing the exposed wood to discolour and degrade under the stresses of the environment (namely students, and all of the various environmental hazards that come with them-tracking in grit and dirty water 

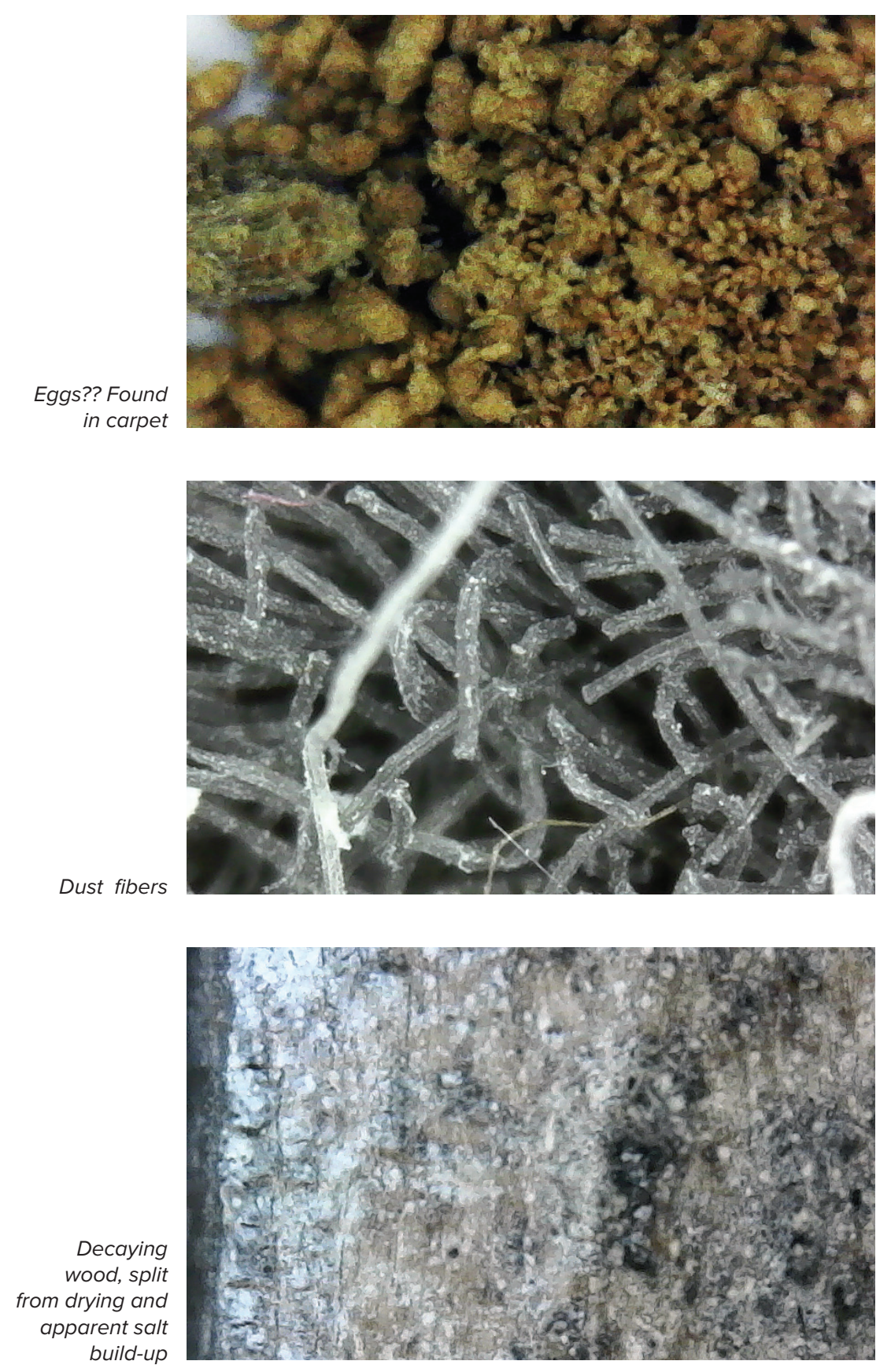

from the outside, spills from food and drink, wear caused by the friction of walking, and many, many more).

In the Architecture Building, but also in the majority of our built environments, this kind of degradation is unfailingly perceived as a failure, not a feature of the built space. Such perception in turn triggers a determined, ultimately failing battle to arrest, reverse, or at the very least cover up a process of decay that is inherent in the material itself. 


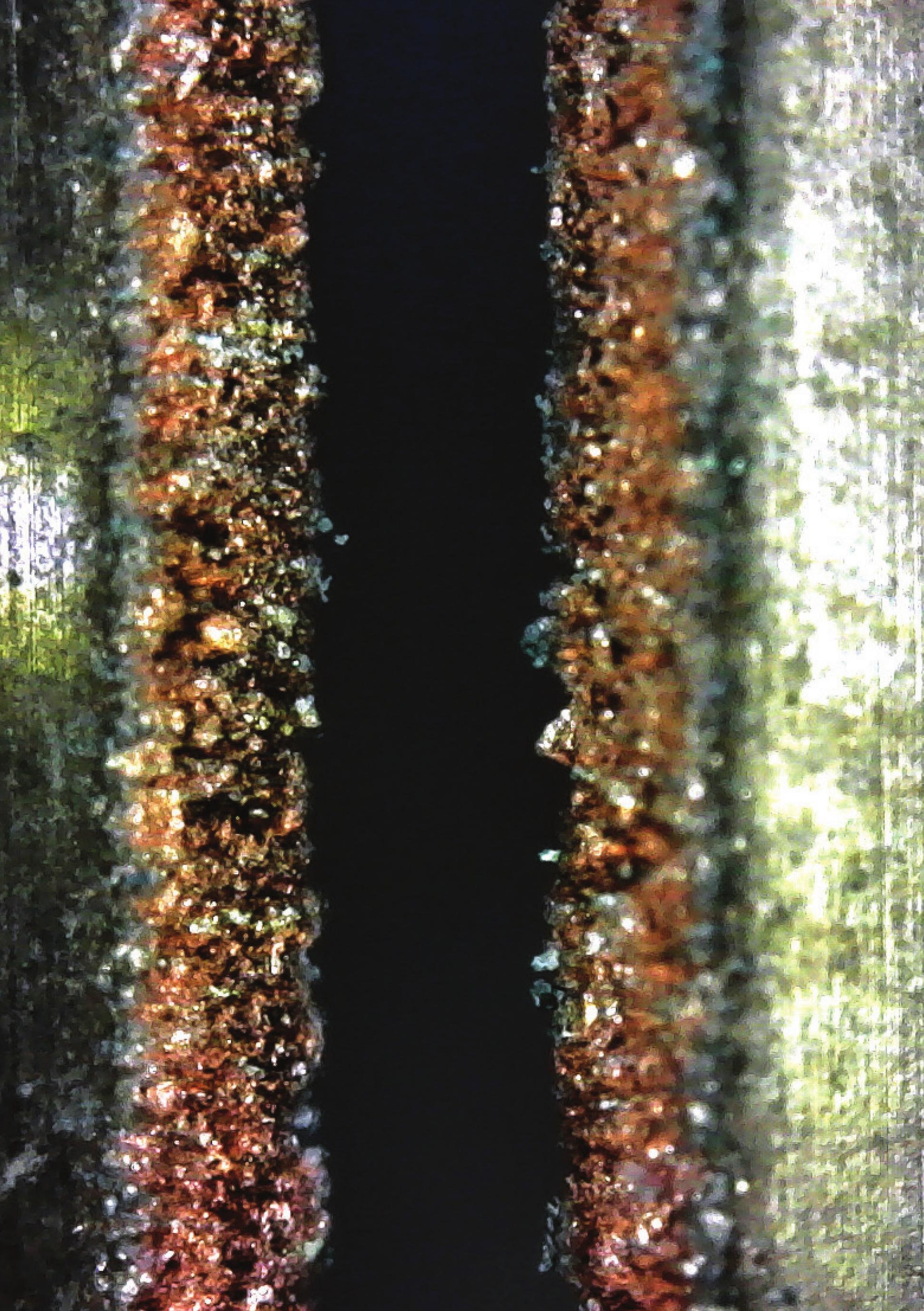




\section{Preface to Proposed Design}

When I began the material experiments, I knew I would eventually be looking to design a project using the toolbox of material decay I would be creating, but I hadn't come with a preconceived notion of what that project might be. I wanted the processes and my research to guide my decision. That said, over the course of the first semester working with the material experiments, I was struck by the beauty of watching the materials-what I found most fascinating was not the end results, but the actual process of change and observation.

In November 2018, as I was wrapping up the first semester and trying to decide how to proceed, I attended a play at the Great Canadian Theatre Company. During the play, I was struck by the non-replicability of what I was seeing. Unlike going to a movie theatre where the audience sees the same material edited, perfected, and displayed time and time again in exactly the same way, no matter where it's shown or who the audience might be, the experience of watching a live play on stage was by its nature completely unique. Although the play had been scripted, rehearsed, and performed in previous iterations, the version I saw that night had never been performed before, and would never be performed again. The exact facial expressions, the visual cues, the interactions between the audience and the stage would be utterly impossible to recreate. It was also the element of risk and surprise that struck me: an actor could miss their line, a prop could be misplaced or broken, costumes could tear. How would the actors respond? How would the audience react? There was no way of knowing, and this enhanced the experience, making it both less perfect and more personally engaging.

When I came out of the play, I began to understand that the play I had just attended and my study of material decay shared a number of important characteristics: impermanence, variability, ethereality. I knew what my 


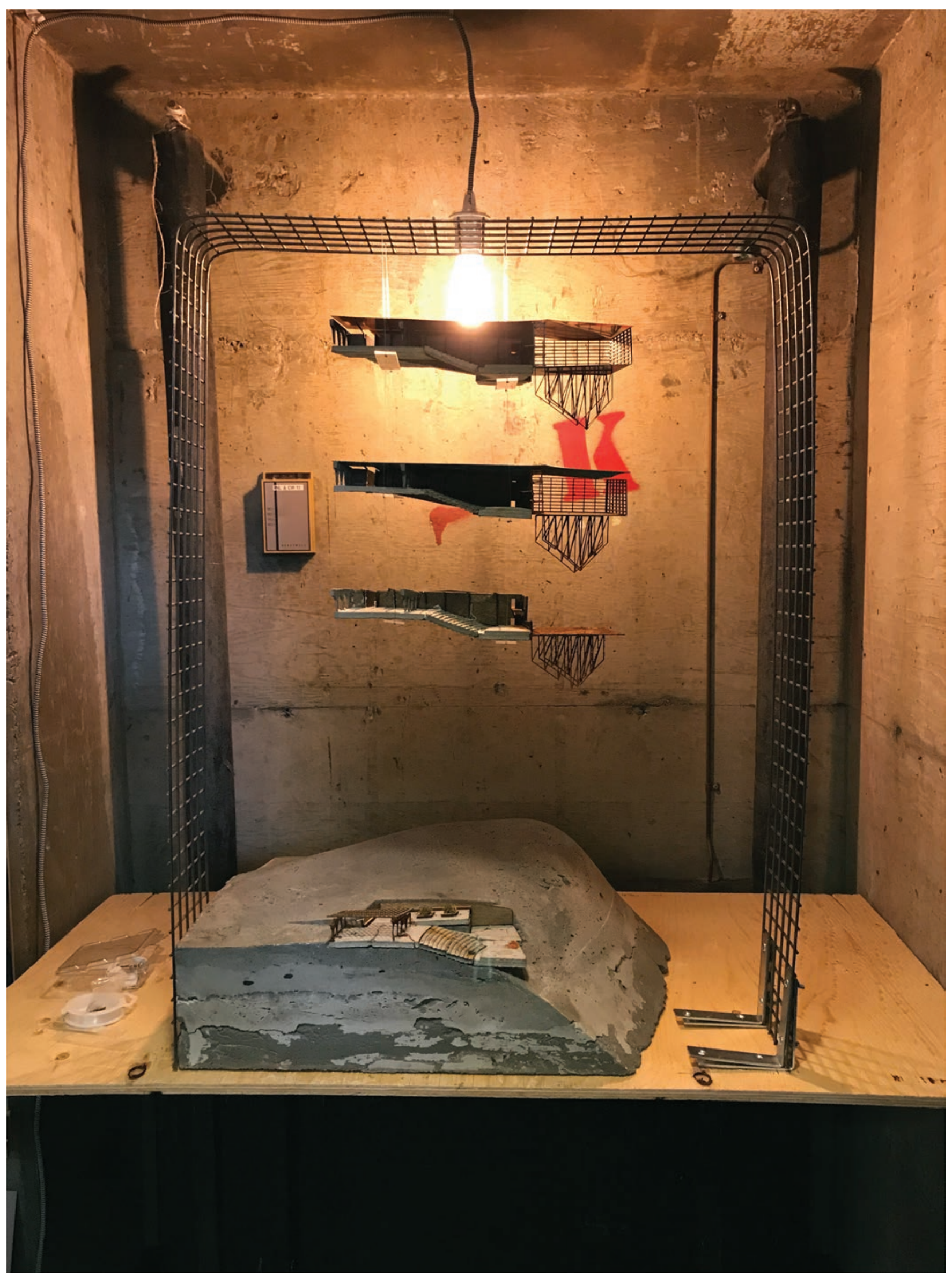




\section{PART 1: EXPERIMENTAL ARCHITECTURE}

Having completed research into the process of degeneration during the first semester, my investigations turned towards the idea of degeneration as expressed in the book The Empty Space by Peter Brook: "Theatre is always a self-destructive art, and it is always written on the wind. A professional theatre assembles different people every night and speaks to them through the language of behaviour. A performance gets set and usually has to be repeated-and repeated as well and as accurately as possible-but every day it is seen something invisible is beginning to die."

Architects create sets of drawings-detailed and annotated to a pristine degree-hand them off to the builders, take some beautiful photographs before the public sets foot in the building and ruin everything, pat themselves on the back, then move on to the next project. But the building that the public experience is completely different. What the perfect photographs and renderings of buildings don't take into account is that we don't live in a clean room; we live in a world of dust, decay, and impermanence.

LEFT: model display at defense (photo by author) 


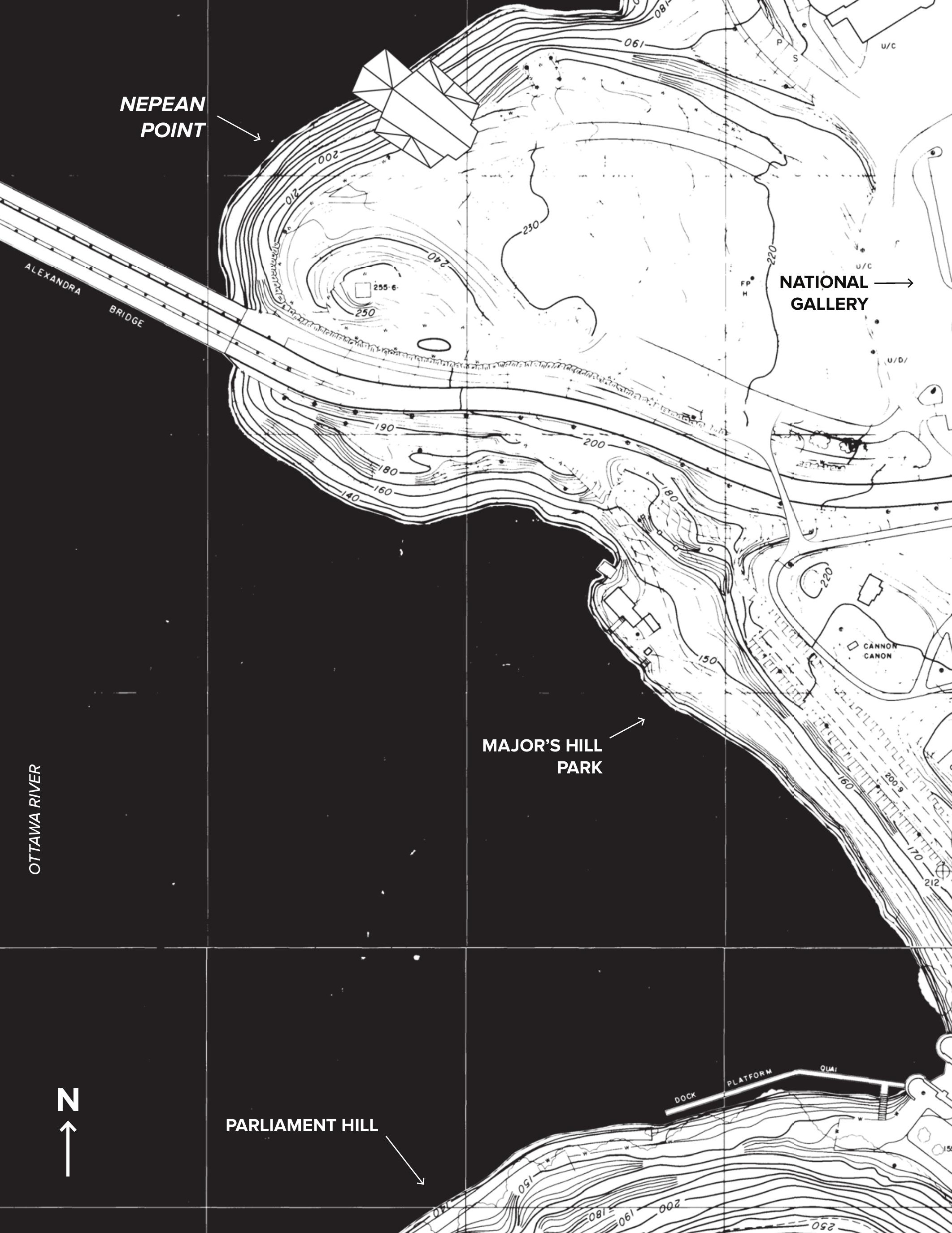




\section{NePEAN POINT}

Nepean Point is located along the Ottawa River, occupying one of the most beautiful geological spots in Ottawa. The point looks out over the Parliament Buildings to the south, Gatineau and the Canadian Museum of Civilization to the west, and both the Alexandria and the Macdonald-Cartier Bridges to the north. In preparation for Canada's centennial celebration in 1967, an amphitheatre was built on the site, and was a popular host to numerous open-air performances and concerts for a number of years. However, with the construction of the National Gallery of Canada on its current site in 1988, access to Nepean Point was effectively cut off from the public path of circulation, and the performances and use of the site stagnated. While the foundation of the amphitheatre remains legible on the site today, the area has been fenced off since the demolition plans were announced in 2011.

The site has intrinsic value as one of the most beautiful features of downtown Ottawa, and deserves to be open to the public. It's unfortunate that such a beautiful site should be cut off from pedestrian thoroughfare, removed from sight and effectively inaccessible to the public. When the Astrolabe Amphitheatre was in use, Nepean Point was a natural gathering spot, a peaceful and scenic respite from the rush and traffic of the ByWard Market and Lowertown. Now it lies cut off from view, and is rarely used or even seen.

LEFT: Site map, adapted (Carleton University 1971 (Note: not to scale)
The National Capital Commission held a competition for a redesign of the site in January 2017, and the winning submission, "Big River Landscape," 
submitted by Janet Rosenberg \& Studio Inc. with Patkau Architects, was announced later that year. At the time of writing this, no further moves have been made by the NCC to go forward with the redevelopment and the site remains stagnant.

\section{MUTABLE AND IMMUTABLE}

In 1915 a statue was unveiled at the highest point on Nepean Point. A handsome statue of a great Canadian explorer, holding aloft an astrolabe in triumph at discovering these wild and untamed lands; at his feet knelt the trusty Indian guide, ready to serve and protect him from the dangers of the Canadian wilderness... In a city full of statues, this one stands out. Champlain and "Tonto" stare out across the Ottawa River just downriver from Parliament Hill, a spectacular statue on an even more spectacular site.

The only problem with this is that the portrayal of Champlain was based on a false portrait of a French man, the astrolabe he holds is being held upside down, and the lowly "savage" kneeling at the Great Adventurer's feet is a mockery and a caricature of the Anishnaabe people whose ancestors had lived here for millennia long before Champlain was born. Fast forward to the 1990s: the statue of the scout is removed to stand in Major's Hill Park across the road, and Champlain is left to fend for himself on Nepean Point. 
Meanwhile in 1967, the natural beauty of Nepean Point has attracted the planners of Canada's Centennial celebrations to install an outdoor amphitheatre to be used throughout the celebrations to highlight the natural beauty of the nation's capital. In 1988, the National Gallery opens, and the building site cuts off access to Nepean Point. The Centennial celebrations have long since passed; and the site's vibrant use as a public gathering space becomes little more than a memory as the amphitheatre is scheduled for demolition.

In Ottawa history, Nepean Point has always represented the comings and goings of the human built environment upon a landscape that has remained static for millions of years. The Champlain and Scout statue-flawed as it was-had its moment to shine, and was eventually split. The amphitheatre, too, had its moment to shine, and is now closed and scheduled to be taken apart.

Whether it is the changing in seasons, and-especially around spring or fall-the changes in weather day-to-day, nature is always in a state of flux. The practice of architectural design attempts to create an immutable monument, unchanging throughout the years, which stand up to the test of time. As a profession, we are therefore attempting to create an immutable building out of mutable materials, placing it in a mutable environment, and trying to stave off the inevitable degeneration that occurs. This seems a bit flawed. 


\section{SITE AS STORY-TELLER}

Nepean Point itself is a well-known landmark in Ottawa, as the former location of the Astrolabe Theatre, as well as of the statue of Samuel de Champlain, which has in its own way told varying stories over the century since it was installed. In its first iteration, the statue depicting one of the earliest Europeans to visit the Ottawa area stood high on the promontory at Nepean Point, staring meaningfully at his (upside-down) astrolabe, while his trusty but nameless First Nations guide knelt at his feet. The statue's original story was one of bravery, nobility, of admiring and even possessing the panoramic view of the river that lay below, with the Gatineau hills off in the distance. The statue's story changed as public consciousness evolved, and the two pieces of the statue were separated-now Champlain stands alone, while the First Nations guide occupies another space at Major's Hill Park. Although the pieces of the statue have been separated, the Champlain statue still resonates emotionally with the thousands of visitors each year who stand on the same site, overviewing a landscape which has changed very little in its fundamentals since the 1500 s.

The point itself is located just north of Parliament Hill, and is the secondhighest elevation along that stretch of the Ottawa River, affording a broad view that has attracted people with its sense of magnified landscape, who might hope to catch a fleeting glimpse of the same view seen by Champlain, whether he actually stood there in real life or not. Although Nepean Point's history is relatively bland-no battles fought, no built history (other than the outdoor theatre), no known events of historical significance-its 
geographical character creates an emotional response in its visitors.

The story told by the original Champlain statue might not have reflected historical reality, but it spoke to the human response to its site; the same can be said of the Astrolabe Theatre, remembered with great fondness by many Ottawa residents and visitors as an outdoor theatre/music venue which took advantage of the same sense of geographical wonder evoked by the location itself, and reiterated in the Champlain statue. Over the past 100 years, the site became an important part of Ottawa's cultural and social landscape, until it was cut off from view and public consciousness by the National Gallery of Canada. This project proposes a return to Nepean Point's acquired function as a place with its own stories, and a place where new stories may be told. 


\section{MATERIAL AS STORY-TELLER}

Everything in the built environment is built from something. Of course, this is as obvious as saying "the sky is blue," but what it means is that every material in our environment comes from somewhere, was put there by someone, and therefore has a story. We see examples of materials with stories all around us: the handrail that's been touched by so many hands the steel underneath the paint has been exposed; the stair that's been walked on so many times a groove has been worn; the doorknob that's used so often it's been burnished to a bright shine. Even if we don't see it happen right away, the very act of inhabitation puts a mark on a building and its component materials over time.

The goal for this thesis, as stated previously, was to create a toolbox of material reactions that then form a project. As such, the materials used in the design for this theatre will be restricted to those experimented on in Part 1, namely: concrete, metal (steel and copper), and wood. Much further research could be done into the degenerative properties of glass, masonry, aluminum, paints, sealers, fabric-and so on-however for the purposes of this thesis, the three primary materials will constitute the primary palette.

LEFT: Progress shot of decaying models (photo by author) 


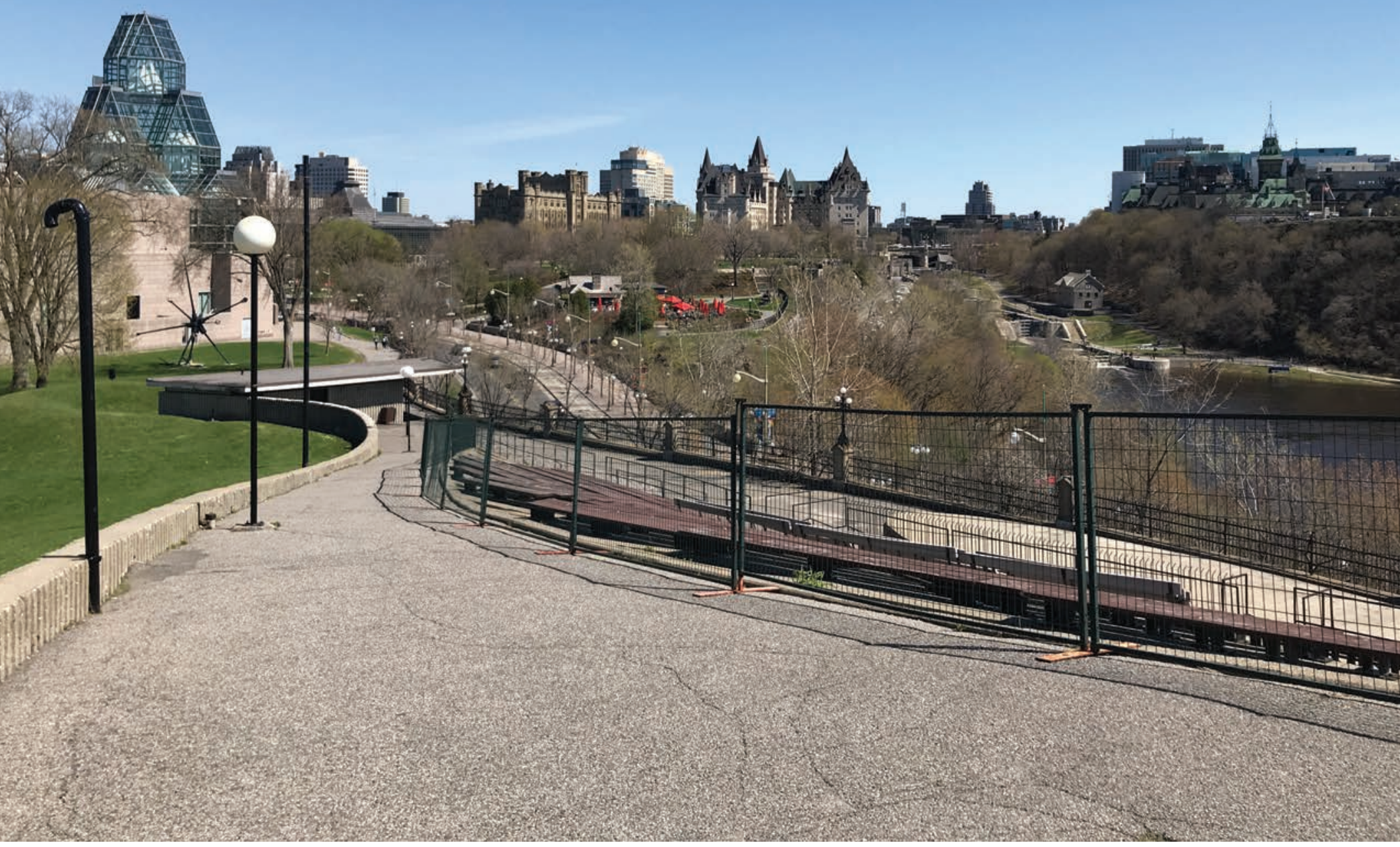




\section{INTERVENTION}

The NCC has stated that their plan for the site is to "improve access and give Nepean Point a unique character that will serve the Capital for the next 50 years." The intervention proposed in this thesis will be a redevelopment of the underlying infrastructure of the site, inaugurated by a temporary occupation of the space by the Local Made-up Theatre Company as a preliminary to a more permanent revitalization of the site. Unlike the typical staggered phasing for an architectural project, defined by clear goals and deadlines, the phasing for this project will take place over the course of approximately 50 years, and will occur in synch with the schedule of decay of the materials that make up the building. In accordance with the NCC's plan for the site, the site plan will also include a bridge that connects Major's Hill Park and Nepean Point, completing the pedestrian circuit that is currently interrupted by the Alexandra Bridge.

Starting with the most permanent changes to the site: the foundation of the theatre will be built from concrete, and will be carved out and nestle into the naturally bowl-shaped rock formation on the north cliff-face. The minimal amount of rock excavated from the escarpment to build the foundation will remain on site, and act as terracing and landscaping. Next: a wood and steel framed structure will clip on to the foundation, acting as the covering for the indoor theatre. As this structure begins to change and fail, it can be easily removed and the site adapted.

As time passes, the building can evolve and be inhabited or dissolved as needed. Rather than treating the site and the building as a linear experience

LEFT: Site photo of Nepean Point, showing fenced-off amphitheatre, and crossing-point for proposed Major's Hill Park/Nepean Point connection (photo by author) (construction, inhabitation, demolition), this project is designed to be treated as cyclical; as the materials in the building begin to decay, the space changes, is reconfigured, reprogrammed, and the cycle begins again. 


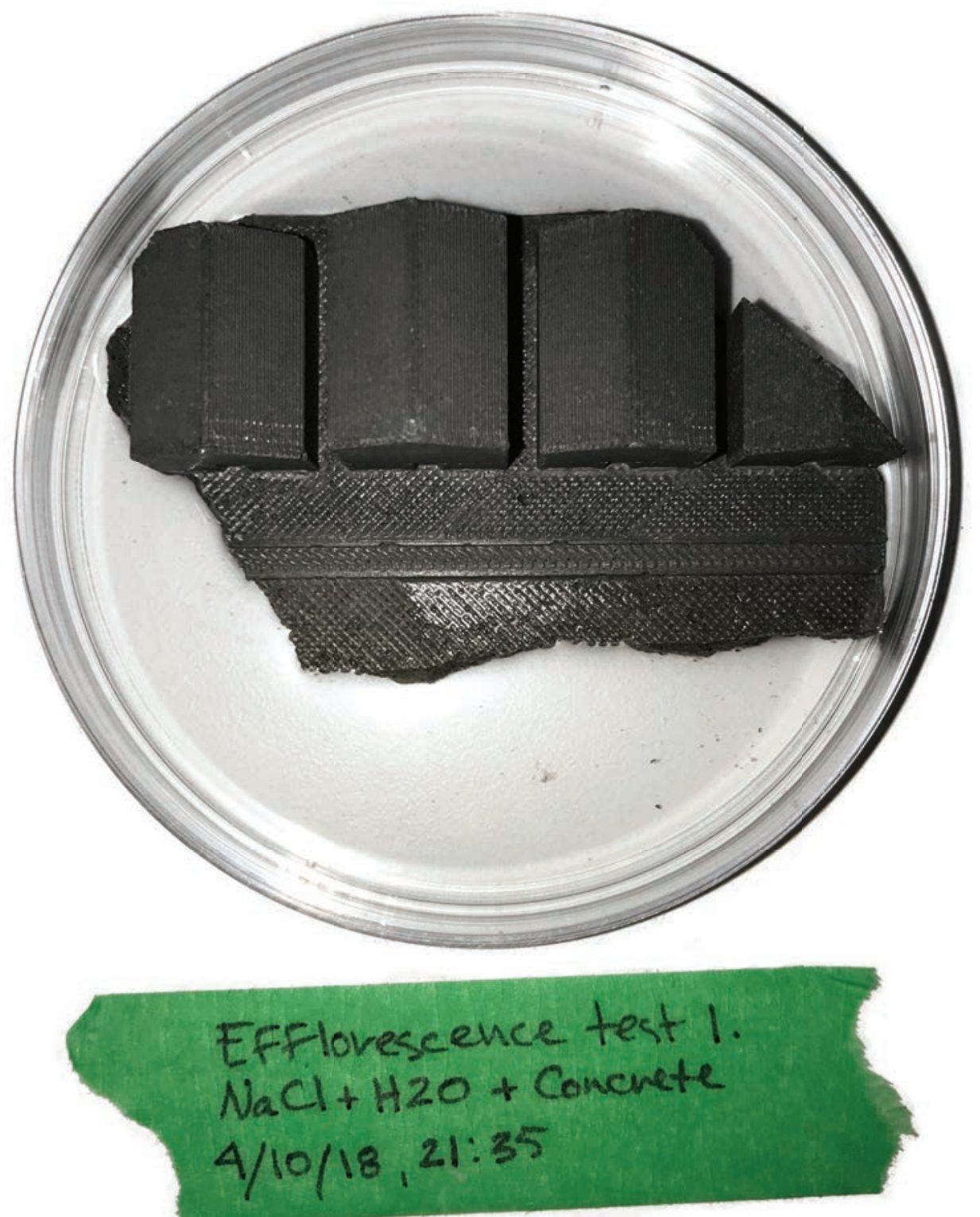




\section{PART 2: MATERIAL THEATRES}

Section 1 went over examples of unintentional decay in the school: things that cause disgust, dismay, concern, and revulsion. But what about the material reactions that can be beautiful? The patinas, the intricate patterns? This section will describe the material reactions, the processes of how they came about, and the observations during and after the fact, in the style of the scientific method. For consistency in the controls, all of the models described in the experiments were built to the exact same specifications, and are essentially carbon copies of each other (as best as could be managed) in different materials. The following material investigations have been chosen carefully to follow a specific developed set of guidelines. The guidelines are as follows:

The material experiments must

1. be conducted on standard building materials

2. exhibit non-living growth (i.e. not plants)

3. exhibit change over an extended period of time

4. be able to form the reaction within standard deviation of environmental conditions found in Ontario. 


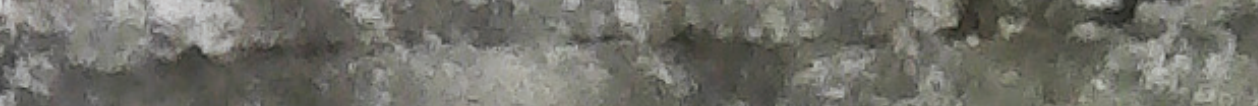

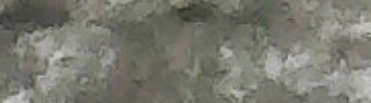

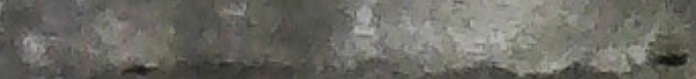

Hest

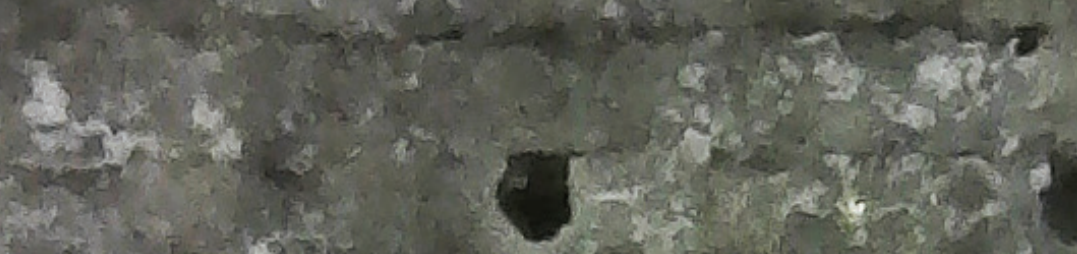
S. 2.

a.t.

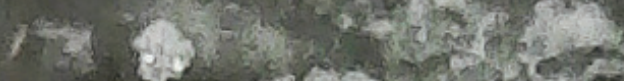

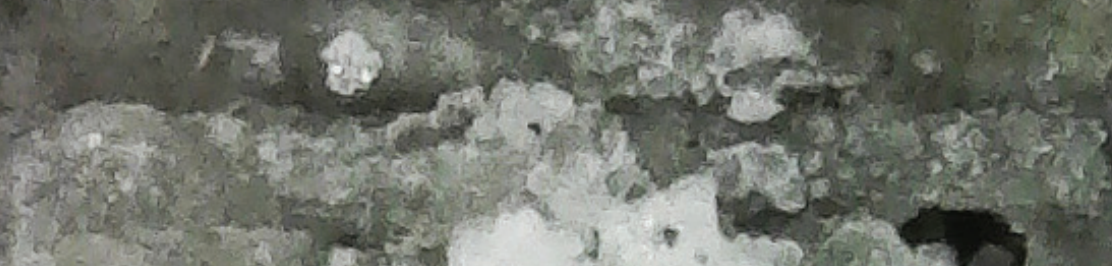

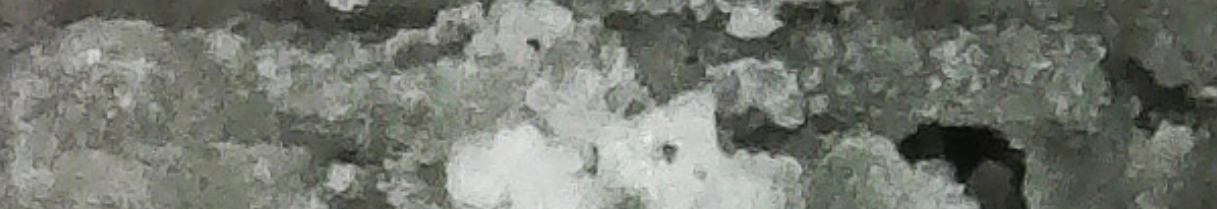

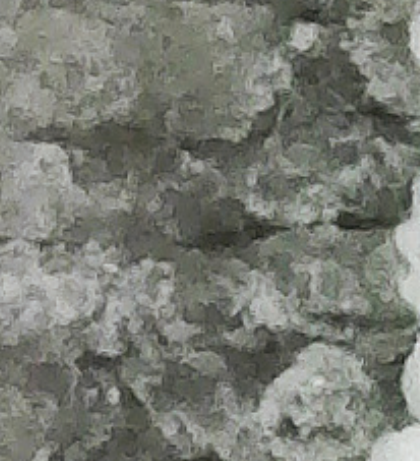

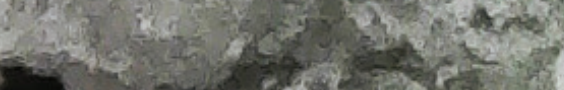

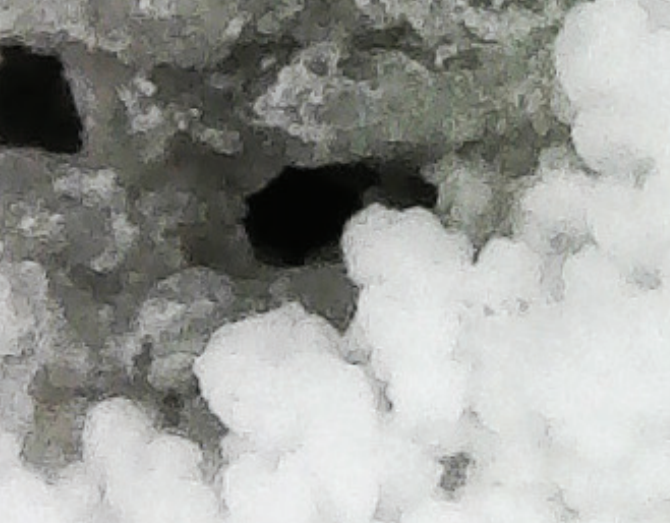

$8 \%$

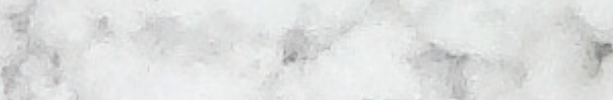

S?

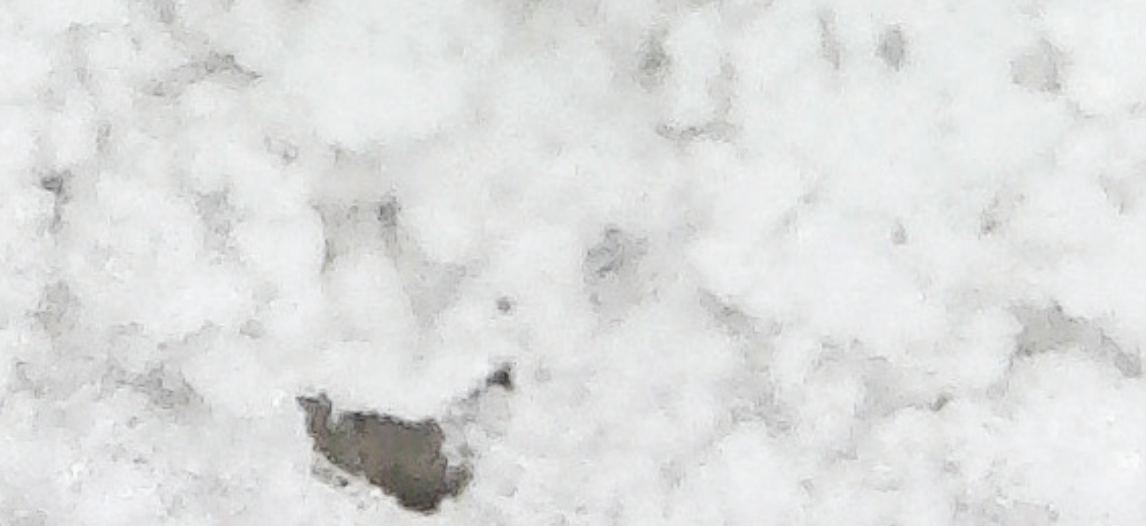

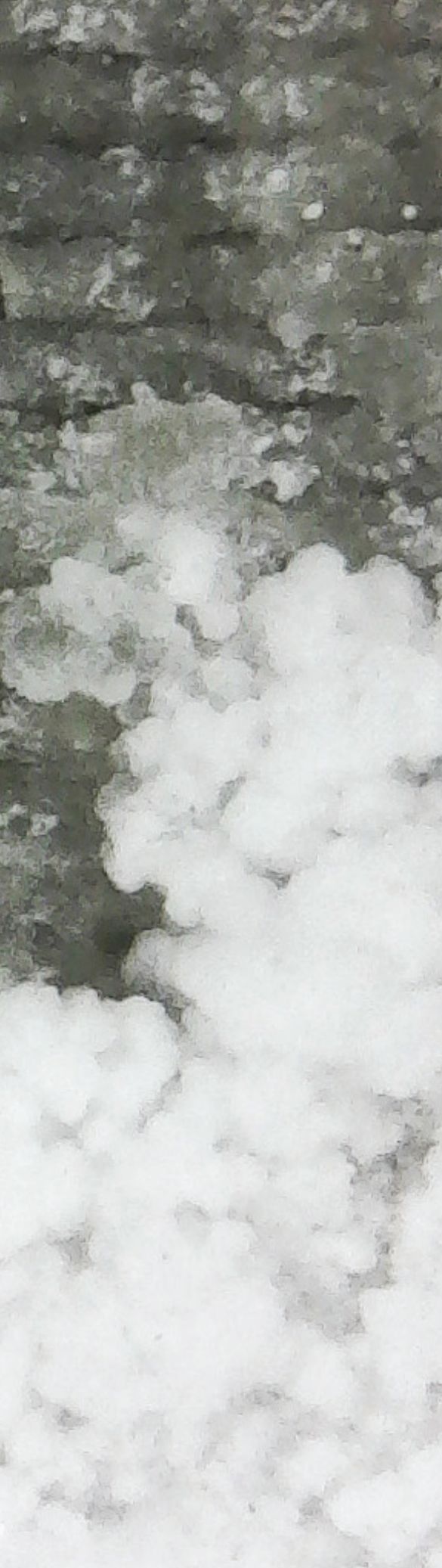




\section{CONCRETE TEST NO. 1}

\section{EFFLORESCENCE}

BACKGROUND RESEARCH: Concrete is a porous material, and as such is prone to absorbing water. When water flows through the concrete via absorption and evaporation, minerals are deposited throughout, and can degrade the makeup of the set concrete. Salt can be particularly harmful, not only as it blooms on the surface and creates unexpected colour changes, but also as the salt corrodes the steel rebar inside the concrete, potentially leading to structural weakening. Salt crystals can also form just inside the surface of the concrete, and as they expand, cause the surface to weaken and crumble.

HYPOTHESIS: Salt will bloom on the surface of the concrete after partial immersion in solution. Full immersion will not be necessary to see growth, as the concrete will soak the salinated water up through its pores.

METHODS: A saturated salt solution was made using three parts distilled water to one part iodized table salt, stirring over high heat for 10 minutes, and allowed to cool. The concrete model was cast using Quikrete Quick Setting Cement, and following the recommended water to powder ratio. The model was allowed to cure under plastic for 48 hours before the beginning of the test. Once the model was removed from the mould, it was placed in a sterile petri dish, and one tablespoon of room-temperature (approx. 20 degrees C) saturated salt solution was added. The model was then left uncovered in the petri dish for 24 hours. After 24 hours, the model was photographed (left). Another one tablespoon of room-temperature solution was added to 


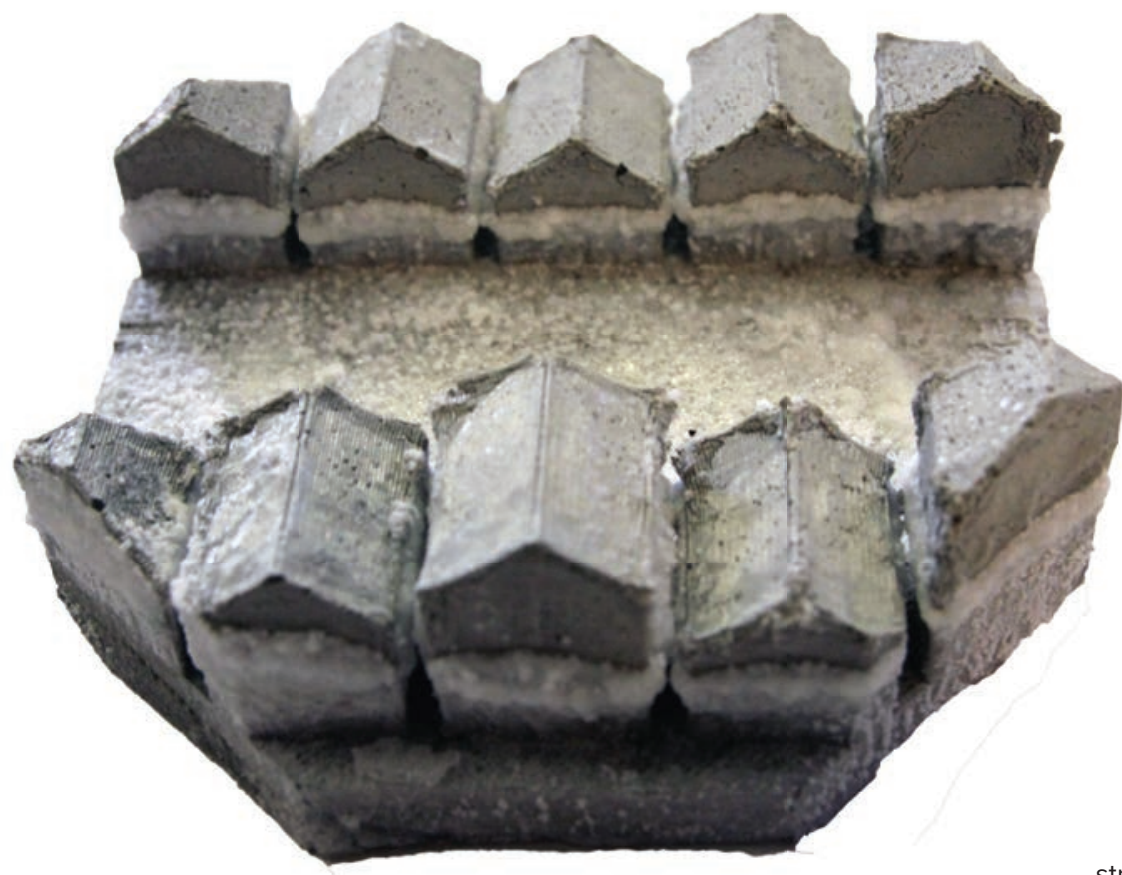

ABOVE: Concrete Test no. 1 test model

BELOW: damage done to internal structure of concrete, 250x magnified

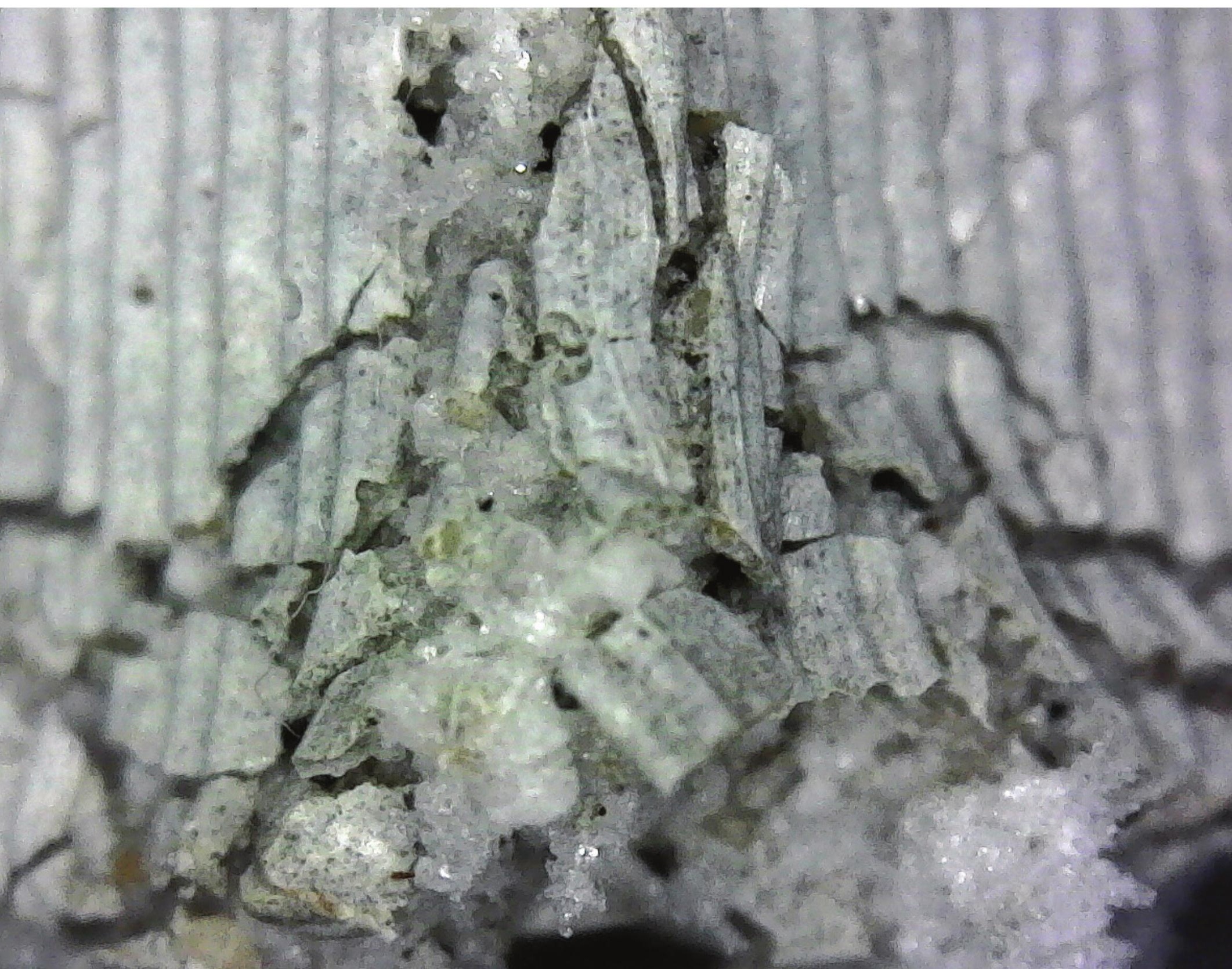


the petri dish with the model, and allowed to evaporate again. This process of checking after 24 hours, photographing, then adding more salt solution was completed a total of four times, after which the concrete had achieved significant salt growth, and the experiment was paused.

OBSERVATIONS: The salt growth occurred much more rapidly than initially expected, taking only 12 hours to show signs of initial growth, and was drawn up through the concrete very effectively. After only one application of salt water, the concrete exhibited salt growth, and after two repetitions of the salt addition process, the concrete was completely obscured by salt growth. In the samples tested, it was obvious where the liquid solution was added-there is a distinct line of much thicker/denser salt crystals approx. 3/4" high on the model, under which the crystals are slightly sparser. Another observation of note is that the upper edges of the concrete model, which was initially crisp and smooth, are now crumbling and cracked, due to the salt crystals forming beneath the surface. 


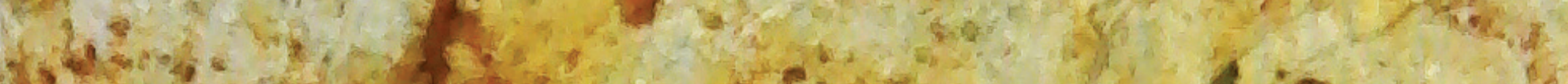

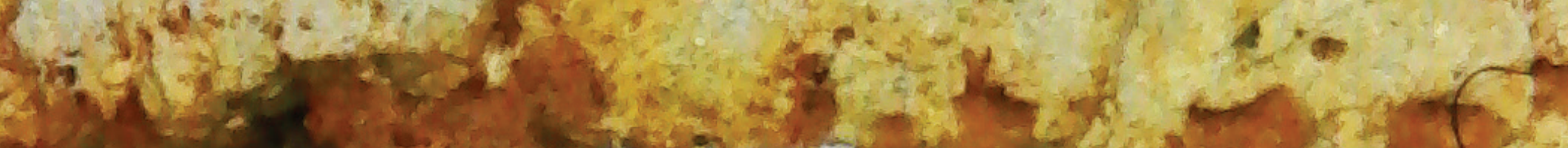

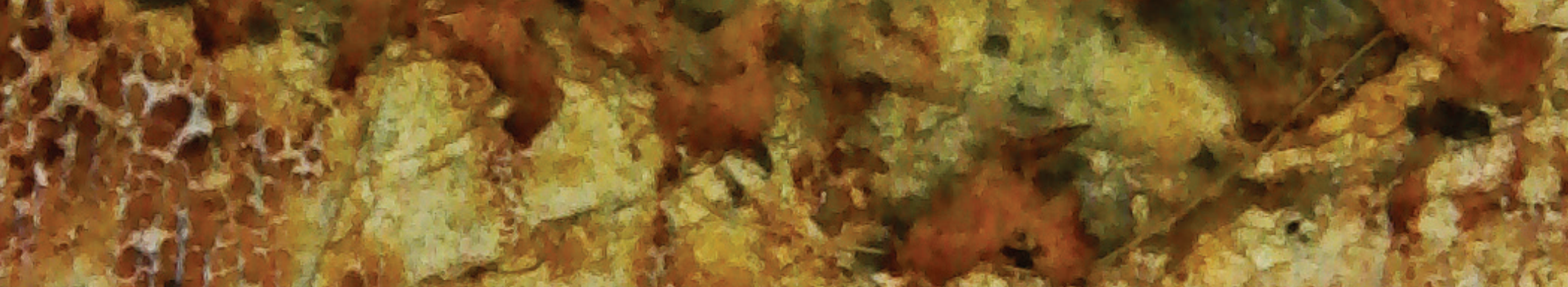

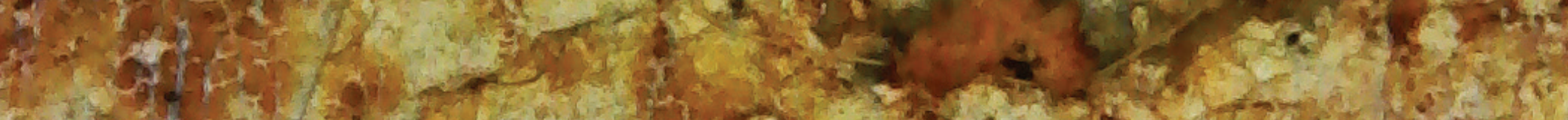

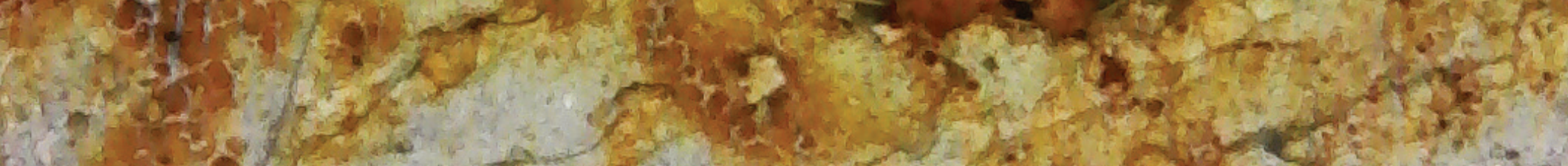

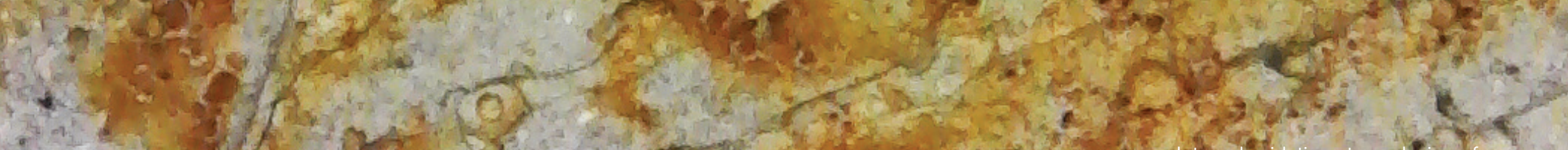

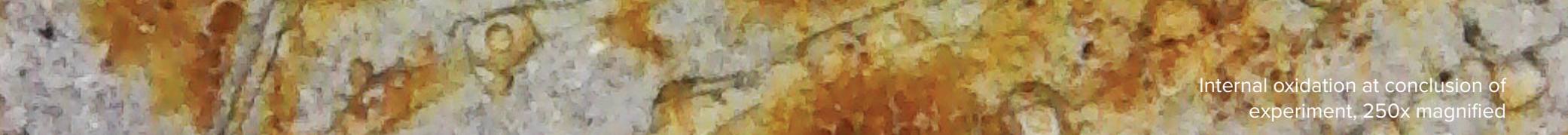

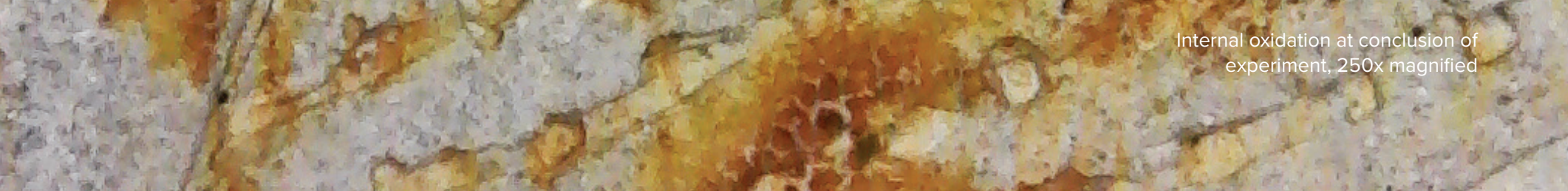
- $18=0.08$

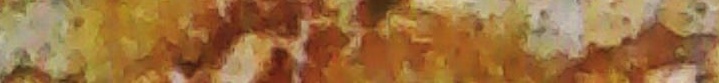




\section{CONCRETE TEST NO. 2}

INTERNAL OXIDATION

BACKGROUND RESEARCH: Another common problem that stems from concrete's ability to soak up moisture is one that comes from the material we use to reinforce concrete: steel rebar (reinforcement bars). The most common type of rebar is made from carbon steel (Benner-Nawman, Inc. 2017), though epoxy coated or galvanized steel is also available at a higher price. As background research for this experiment, galvanized steel wire and raw steel wire were submerged in a slightly acidic solution to observe the oxidation process at an accelerated rate. These experiments resulted in an almost complete dissolution of the structure of the steel-given more time exposed to these elements, it is likely the steel would be reduced to nothing more than oxidized sludge.

When rebar corrodes, the resulting oxidation (rust) expands and tends to flake away from the initial substrate, cracking the concrete from the internal pressure and causing it to loosen from the supportive rebar. As the concrete cracks, the internal reinforcements of the structure are exposed to external elements, compounding the problem. More information on steel oxidizing can be found in the later section, metal test \#2.

HyPOTHESIS: Steel "rebar" (galvanized steel wire) was embedded within the concrete as it was cast to reinforce the thin concrete. After exposure of the concrete to oxidation accelerator, it is likely that the structural integrity of the base of the model will be seriously compromised, possibly resulting in a breakage. 


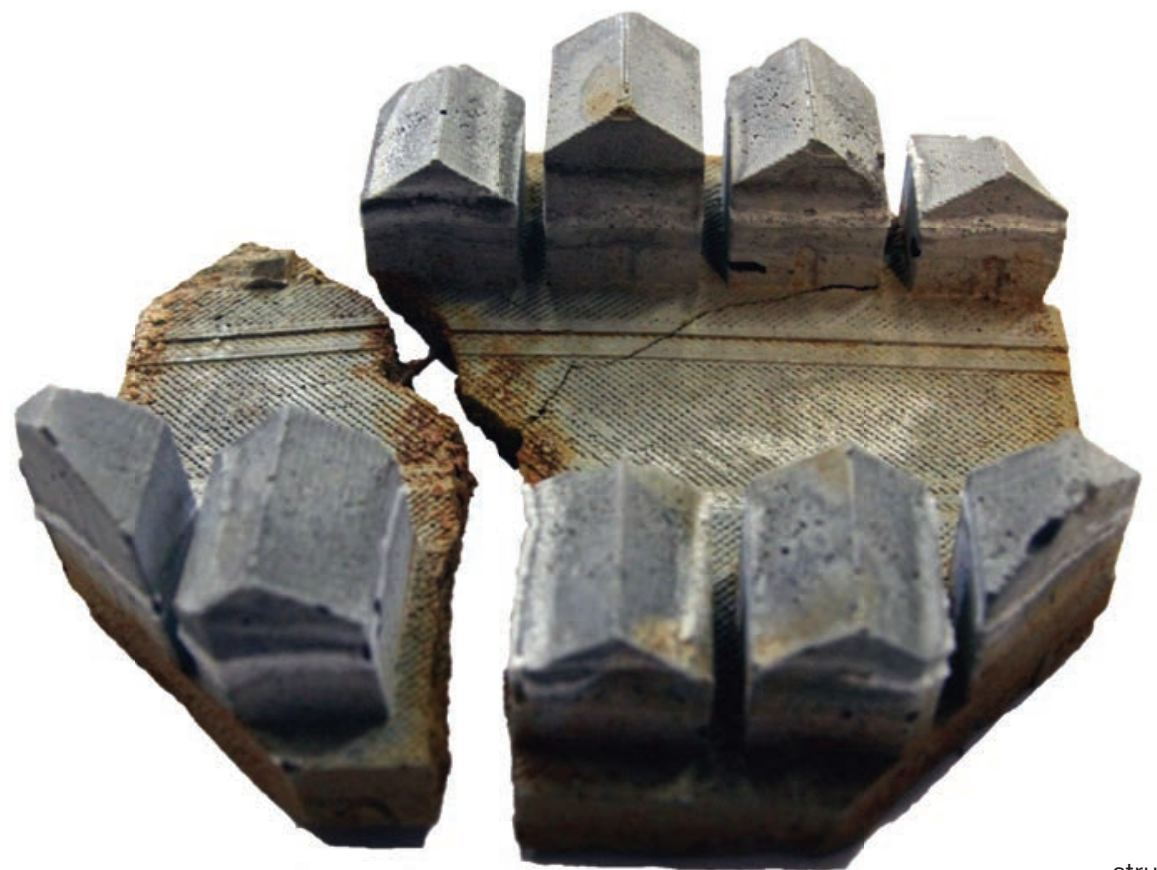

ABOVE: Concrete Test no. 2 test model

BELOW: damage done to internal structure of concrete, $250 x$ magnified

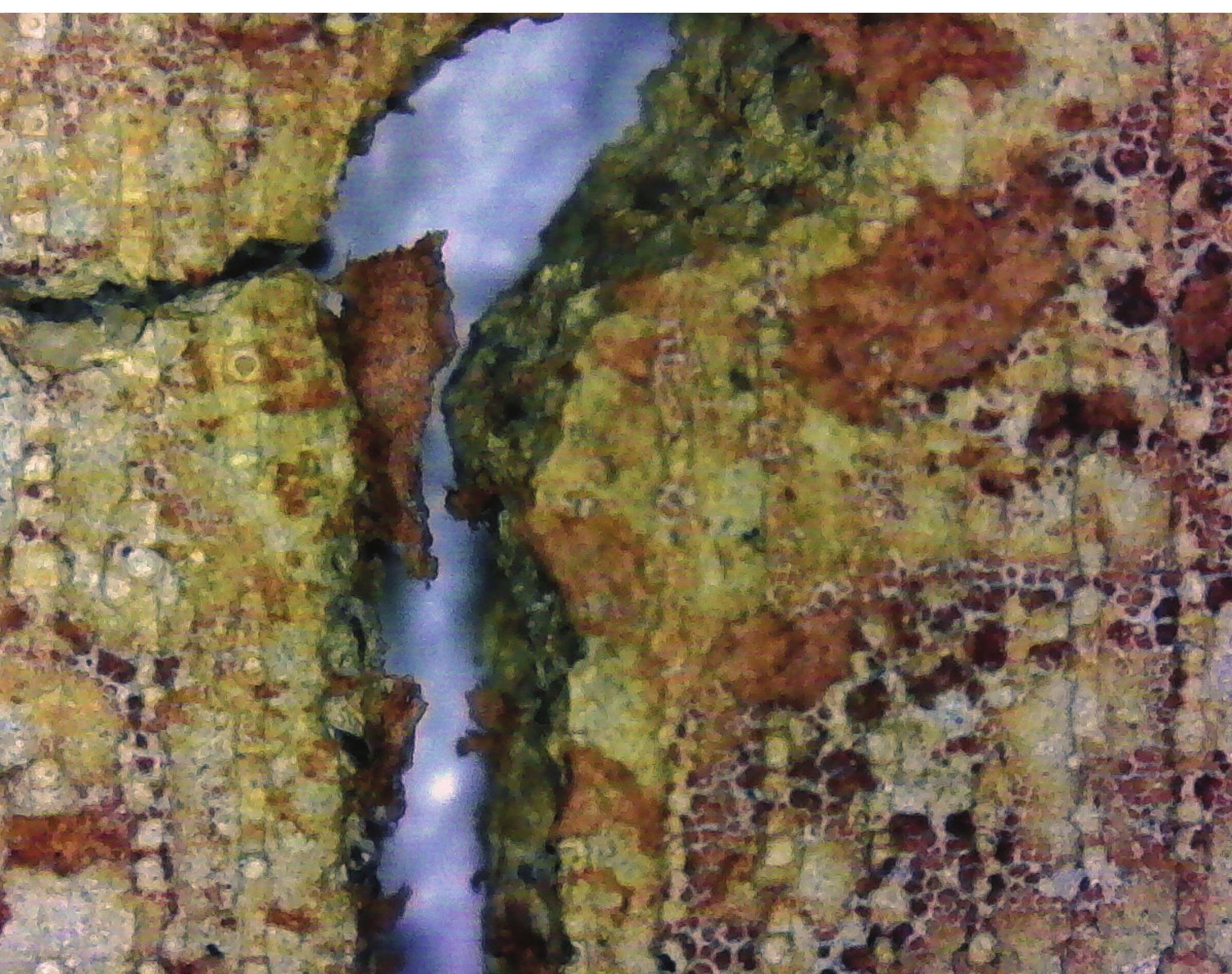


METHODS: As with the previous concrete test, the model was cast using Quikrete Quick Setting Cement, and following the recommended water to powder ratio. The model was allowed to cure under plastic for 48 hours before the beginning of the test. While the concrete was still wet (within 10 minutes of casting), small pieces of galvanized steel wire were embedded in the cement to simulate the effects of rebar placed in concrete during casting. The model was then set to soak in three tablespoons of an oxidation accelerator solution made from 20 parts hydrogen peroxide (3\% strength), three parts white vinegar (5\% strength), and one part iodized table salt. In the preliminary experiments to test how the galvanized wire would react to the solution, it took about 15 days for the wire to show significant decay (colour change, state change), so the concrete model was set to soak for 15 days as well.

OBSERVATIONS: After the model had soaked in the oxidation accelerator solution for 15 days, there was no visible change exhibited in the model. This was a surprise, as at the 15-day mark, the exposed steel wire that had been soaking in the same oxidation accelerator solution had exhibited significant decay. With this in mind, the model was cracked slightly using a hammer, to expose what was happening on the inside. A few points of note upon cracking the model: first, the model was surprisingly difficult to crack, considering the thinnest point of the concrete was only $3 / 8$ of an inch thick; second, after cracking the model open and looking at the wire inside, there seemed to be almost no change in the oxidation process of the wire. The cured concrete had created a protective barrier around the wire, which seemed to be slowing the decay significantly. The model was placed back into the oxidation accelerator solution after it was opened, at which point the wire started to oxidize in earnest. This is an important discovery for the experiment, as it is counter to the original hypothesis. 


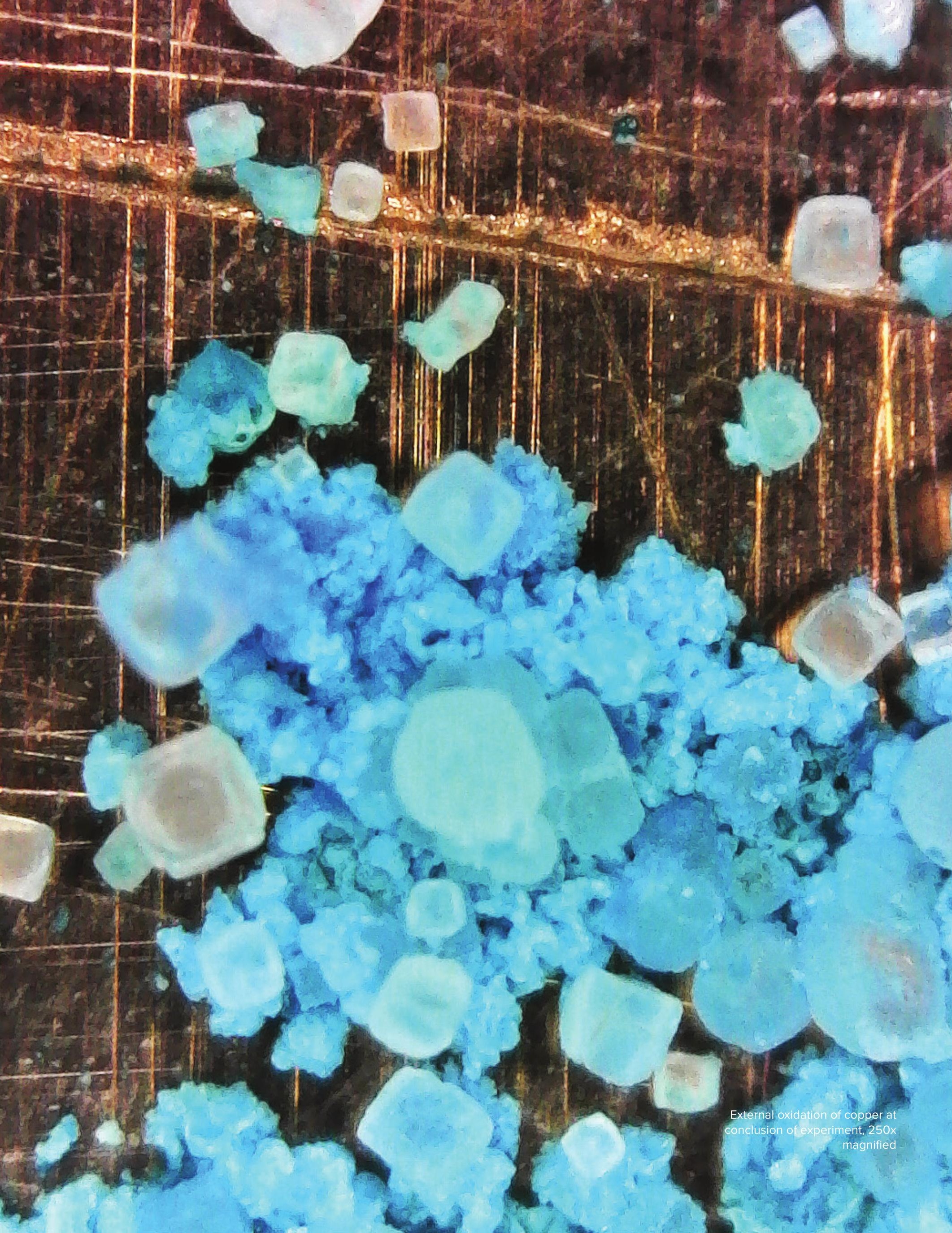




\section{MetAl Test NO. 1}

EXTERNAL OXIDATION

BACKGROUND RESEARCH: Oxidation in copper occurs when the metal is exposed to oxygen-most commonly the oxygen in our air and in water. Exposure to heat and acidic compounds can also induce corrosion. This oxidation is what adds the blue-green colour to copper or copper alloys like brass or bronze. This effect can famously be seen to desirable effect on the roofs of the Canadian Parliament buildings, and many others. Another effect of copper oxidation includes the formation of a protective outer layer that prevents further corrosion-much like burning wood creates a fireproof protective layer on the exterior of the wood, protecting the rest of the interior.

HYPOTHESIS: Upon application of the oxidation accelerator solution, the copper will form a patina that grows over time to produce a green/blue hue on the metal.

METHODS: A sheet of 26 gauge raw copper was cut on a water-jet cutter, and then folded to produce the model. 1 tablespoon of $5 \%$ strength white vinegar was poured into a glass petri dish, the model was placed in the liquid, and then 2 tablespoons of salt was scattered over the model, to initiate the copper carbonate/sulfate mix. The model was left in the solution for overnight, and was checked after 12 hours.

OBSERVATIONS: In the hypothesis for this experiment, it was expected that the reaction on the copper would be fairly small and cosmetic after the 


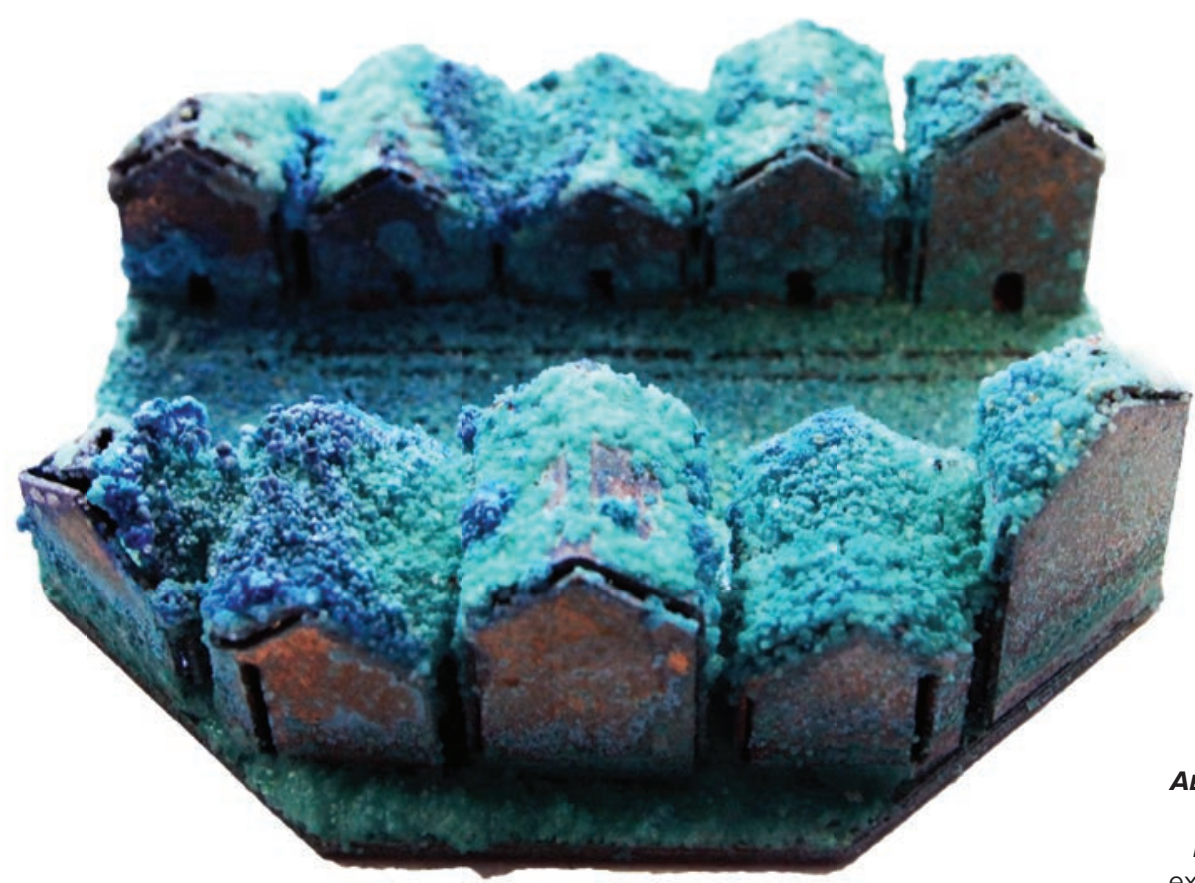

ABove: Metal Test no. 1 test model

BELOW: crystallization caused by external oxidation, $250 x$ magnified

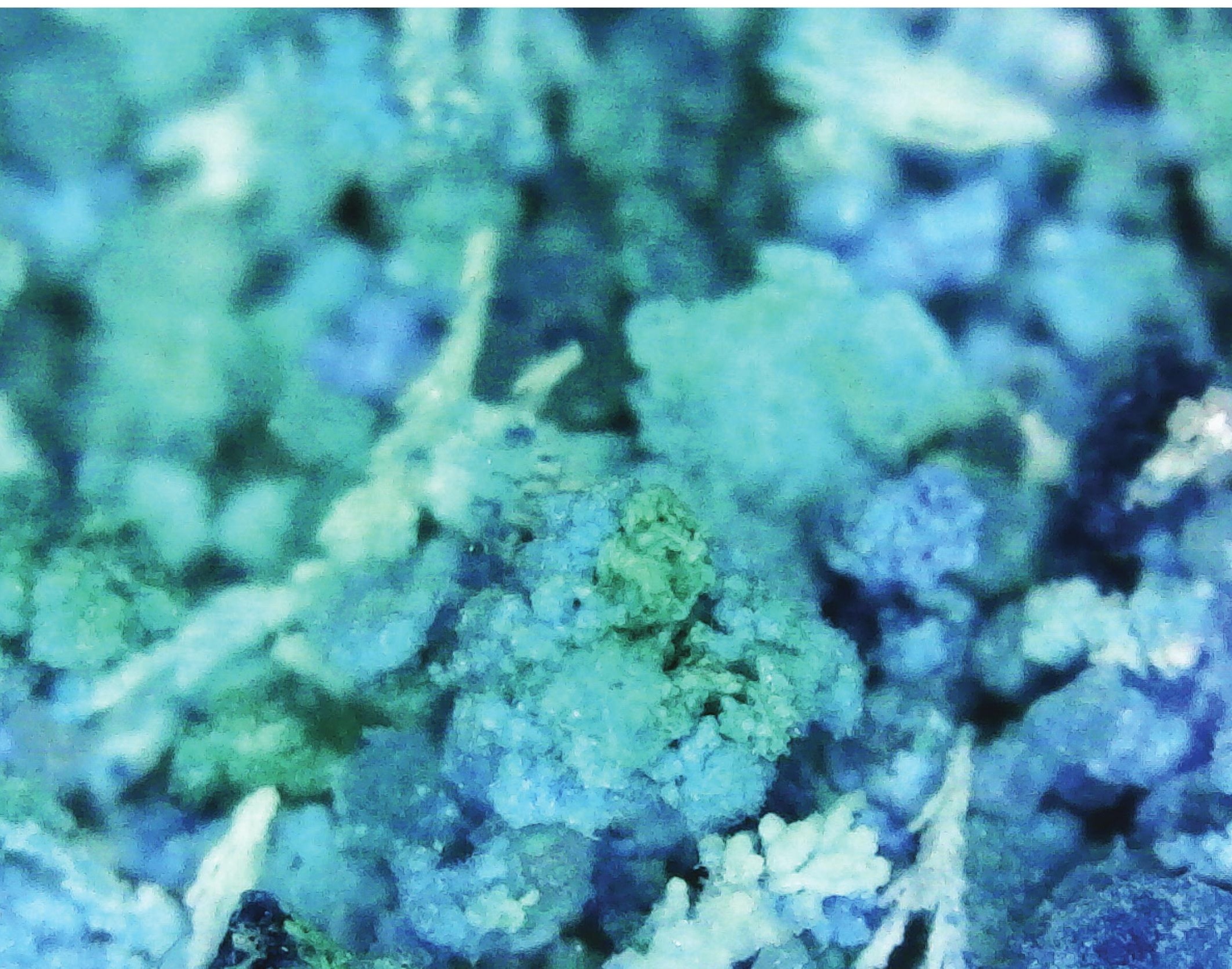




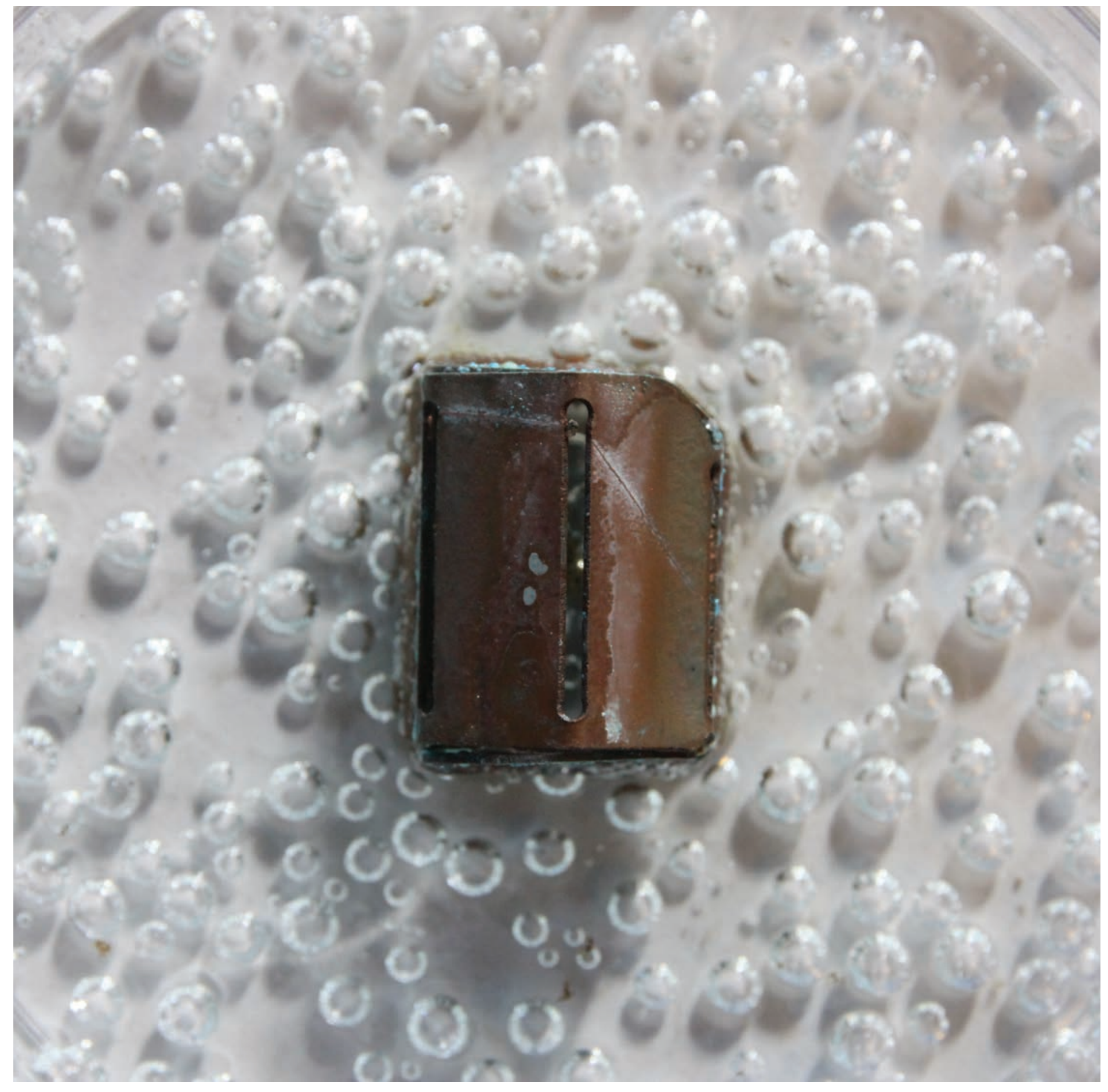

ABOVE: Process photo during oxidation

first day in the solution. However, after 12 hours, the reaction that occurred was significant-as illustrated in the photographs taken with a 250x digital microscope, the salt and vinegar created copious amounts of blue carbonate/sulfates. The experiment was halted after 12 hours, and further salt and vinegar were not added to the model, as it seemed superfluous. 
$+3 x^{2}=0$ -

$x^{2}+2=-12$

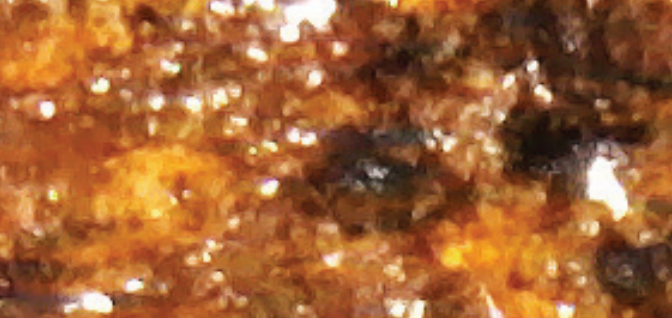

$0.1^{2}+2 \div$

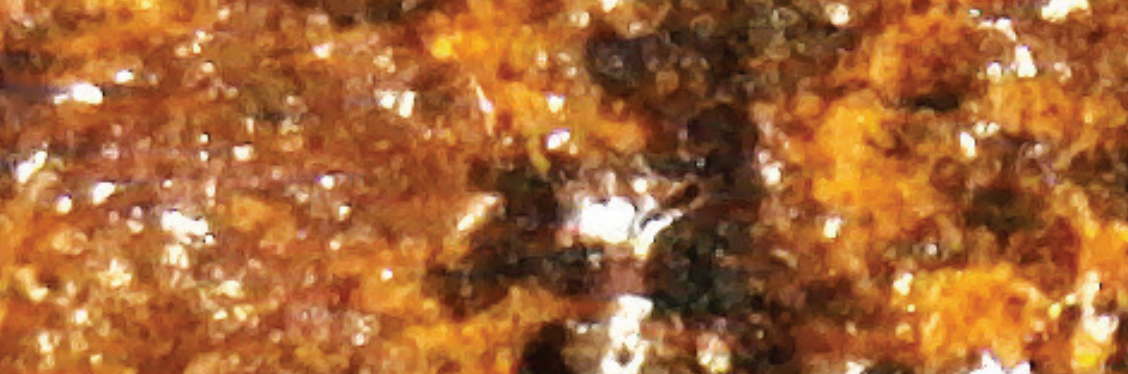

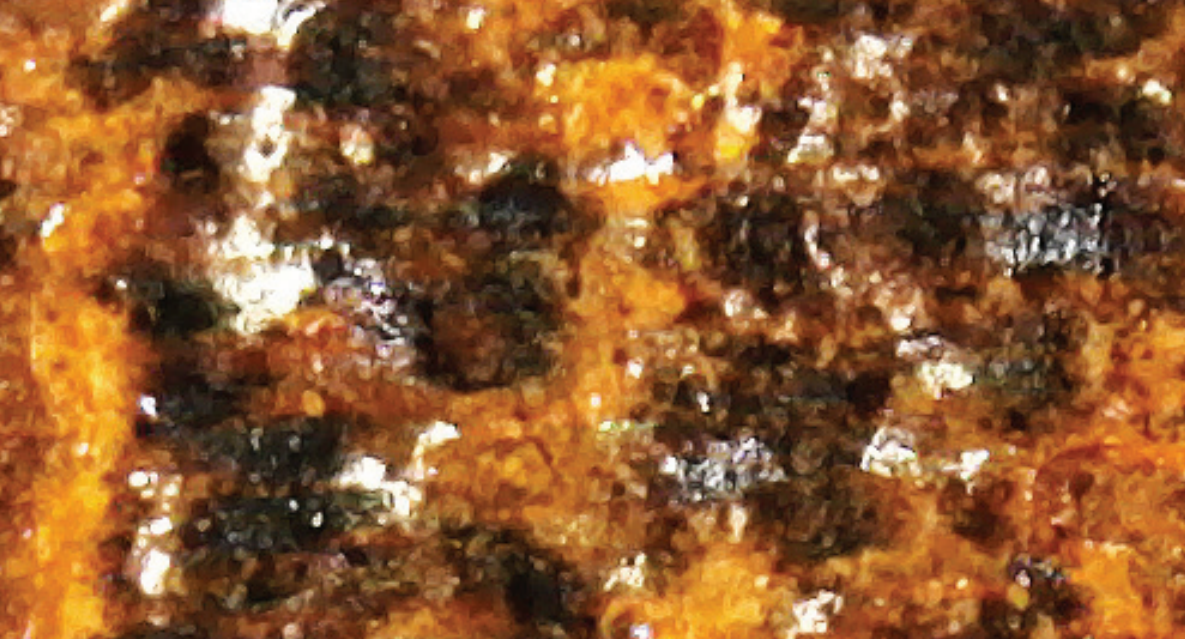

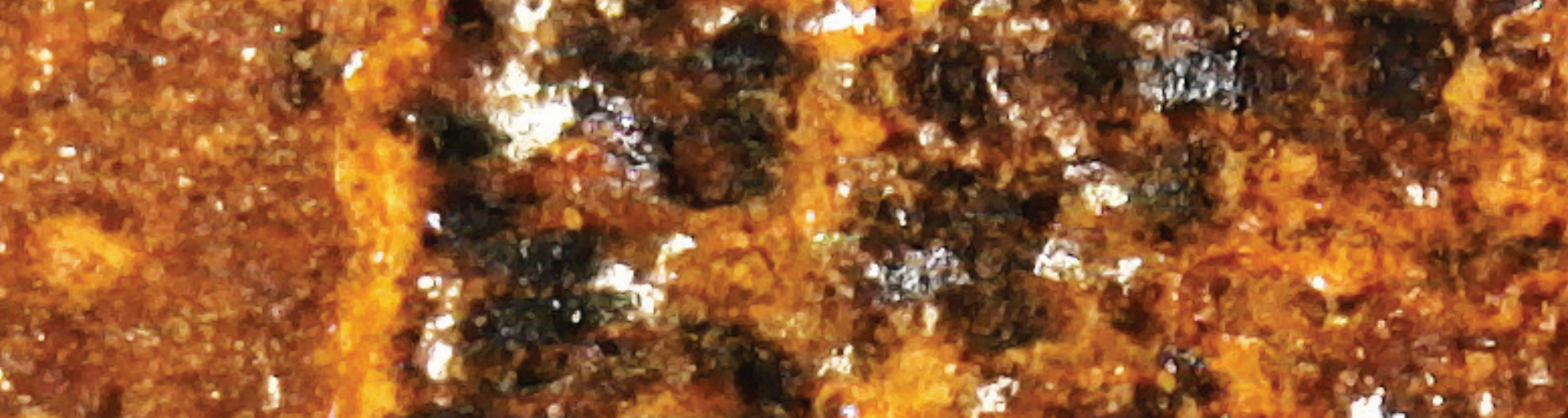

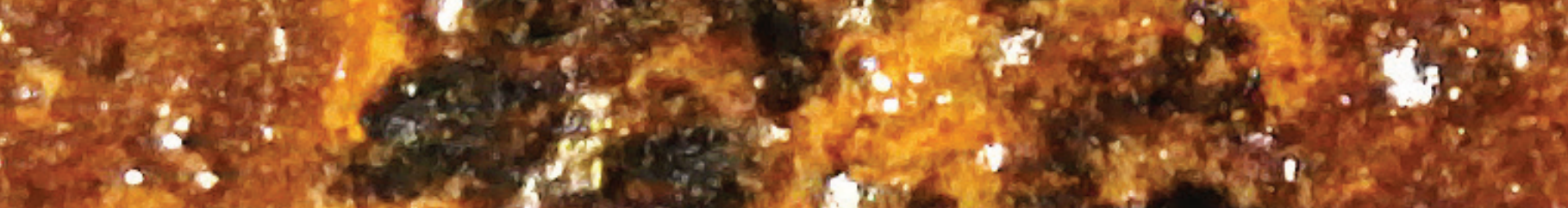

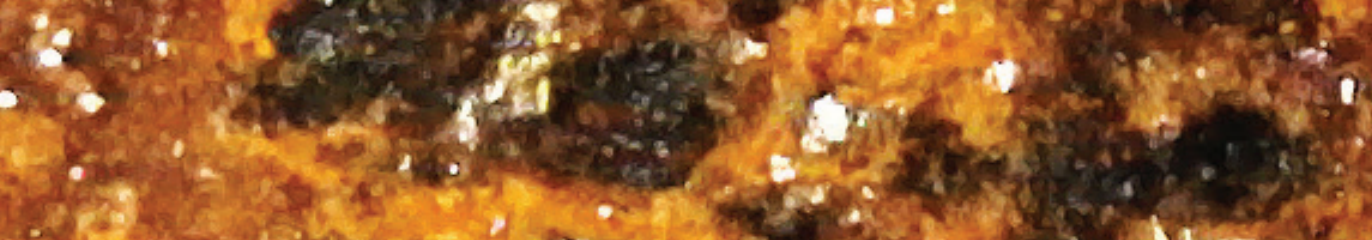

(3)

2. $1 \%$

$$
1+x^{2}+2,
$$

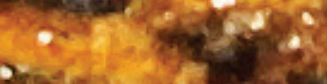

ax.

, .7

$x^{2}=$

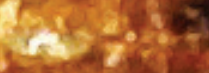

2.

$\operatorname{los}$

3

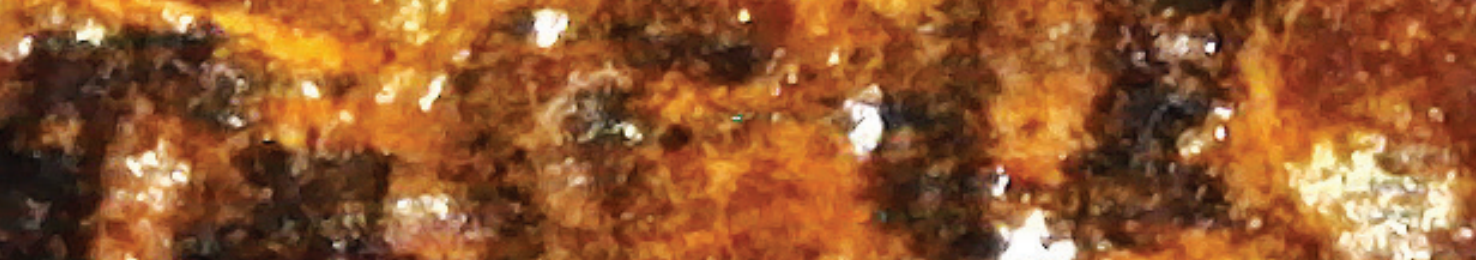

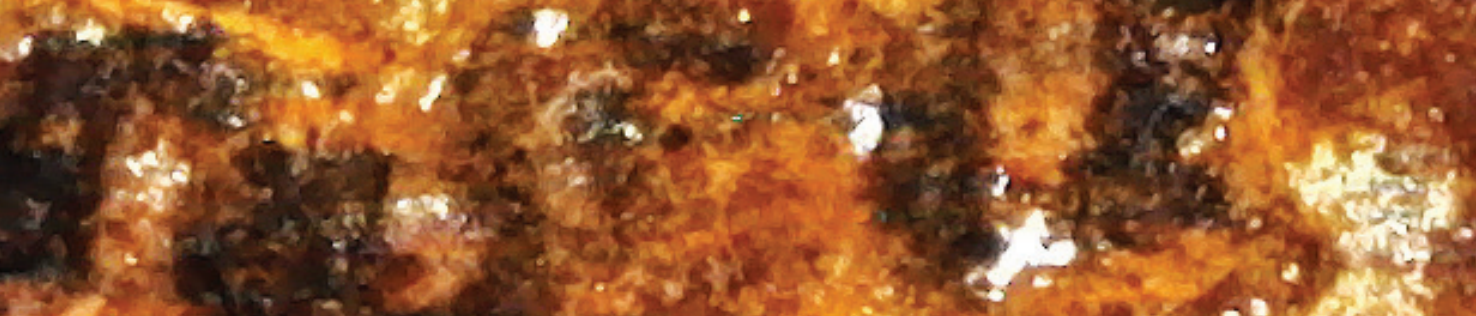

4.8

his:

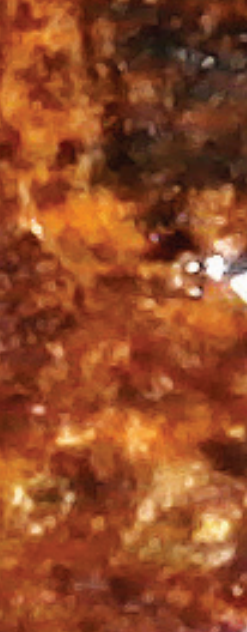

4is

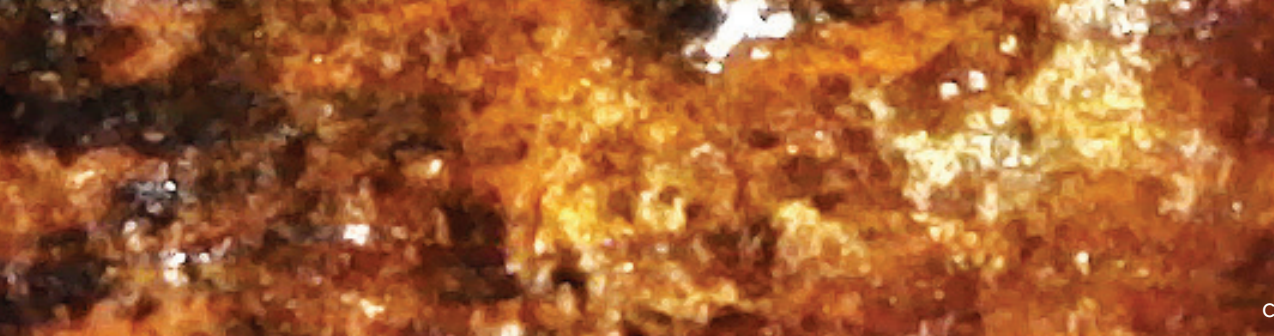

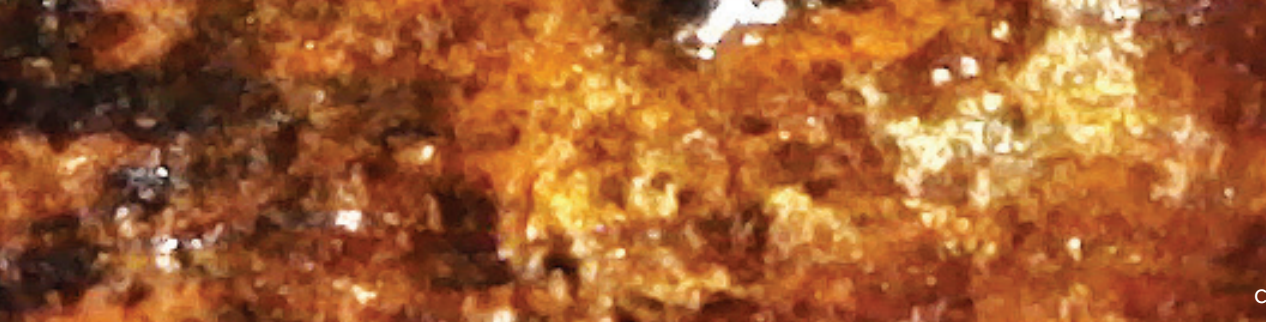

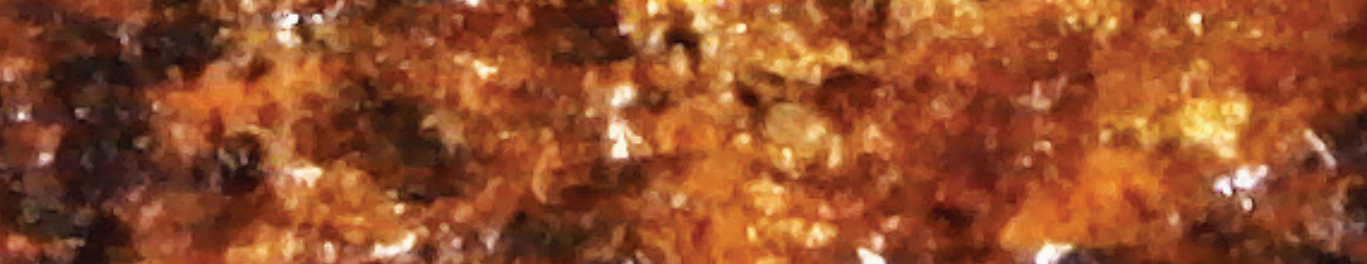

External oxidation of steel at
conclusion of experiment, $250 \mathrm{x}$ experiment, $250 x$

$x+90=23$

ser -51. testified 


\section{METAL TeSt NO. 2}

EXTERNAL OXIDATION

BACKGROUND RESEARCH: Any material made with iron that is exposed to both oxygen and water will rust. Because steel is made almost entirely of iron, it is very much prone to rusting. Steel will rust immediately when being exposed to moisture and air if not protected by anything (galvanization, epoxy). How quickly steel oxidizes is generally dependent on how much oxygen and moisture the steel is exposed to. Oxidation will affect the exterior of steel first, before slowly corroding through the steel surface. Given enough time, all iron in the steel material will oxidize and render the steel essentially useless for its intended structural purposes.

HYPOTHESIS: Upon application of the oxidation accelerator solution, the steel will begin to oxidize and rust. It may take several applications of the solution to form significant decay.

METHODS: A sheet of 26 gauge raw steel was cut on a water-jet cutter, and then folded to produce the model. As described in Concrete test \#2, a solution of 20 parts hydrogen peroxide (3\% strength), three parts white vinegar ( $5 \%$ strength), and one part iodized table salt was mixed, to produce an oxidation acceleration solution. The steel model was sprayed with approximately 1 tablespoon of this mixture, using a typical household spray bottle set to mist. The spray bottle was used to ensure even coverage on the surfaces of the steel. The model was left to sit with the oxidation accelerator solution on it overnight (approximately 12 hours), and the solution was allowed to evaporate. After 24 hours, the model was doused 


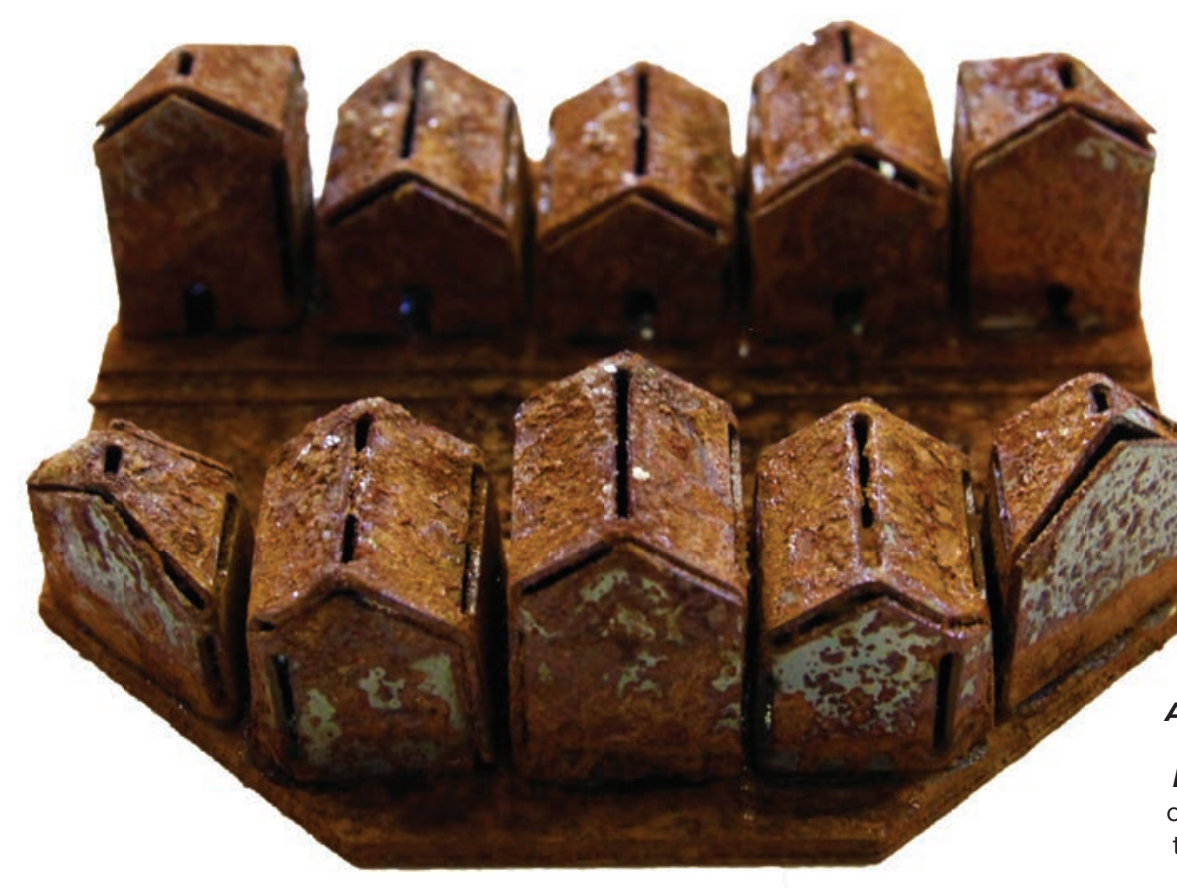

ABOVE: Metal Test no. 2 test model BELOW: time lapse photography of oxidation process, 250x magnified, time interval: 30 seconds between photos
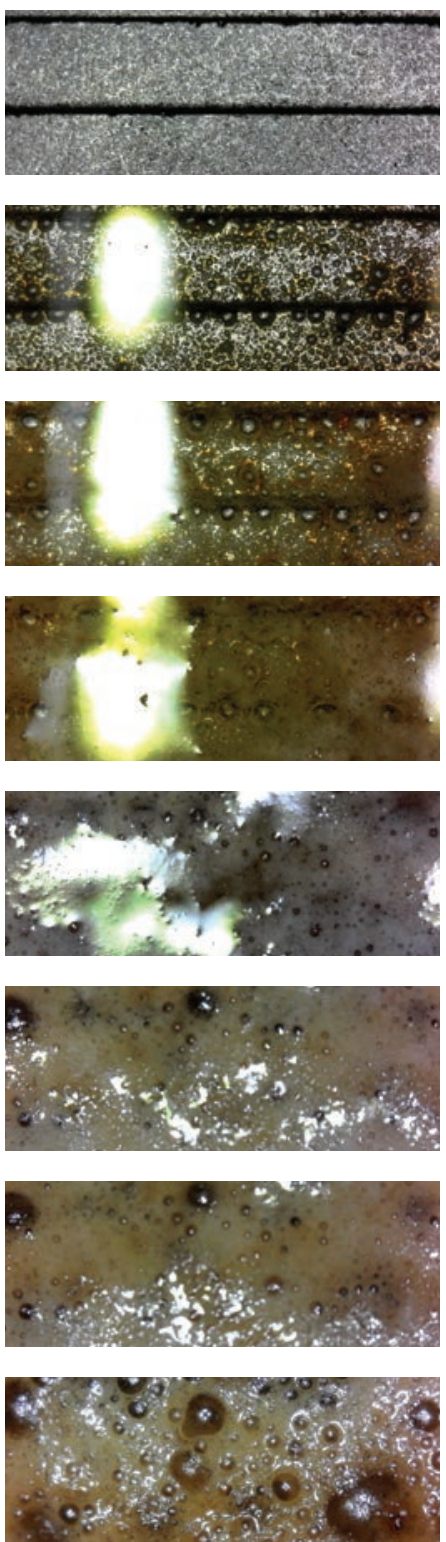
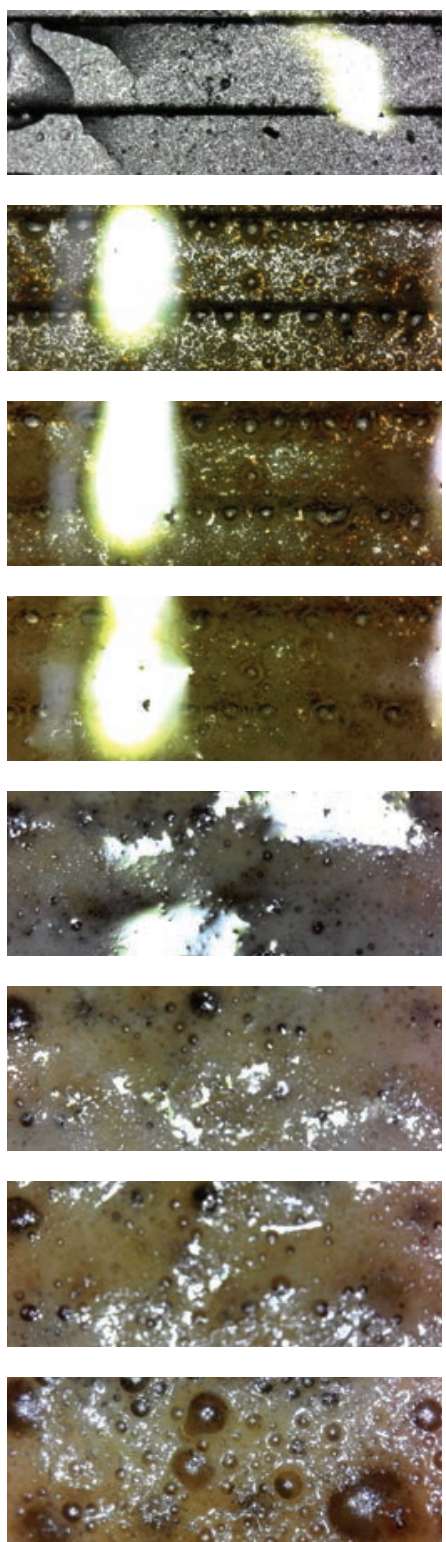
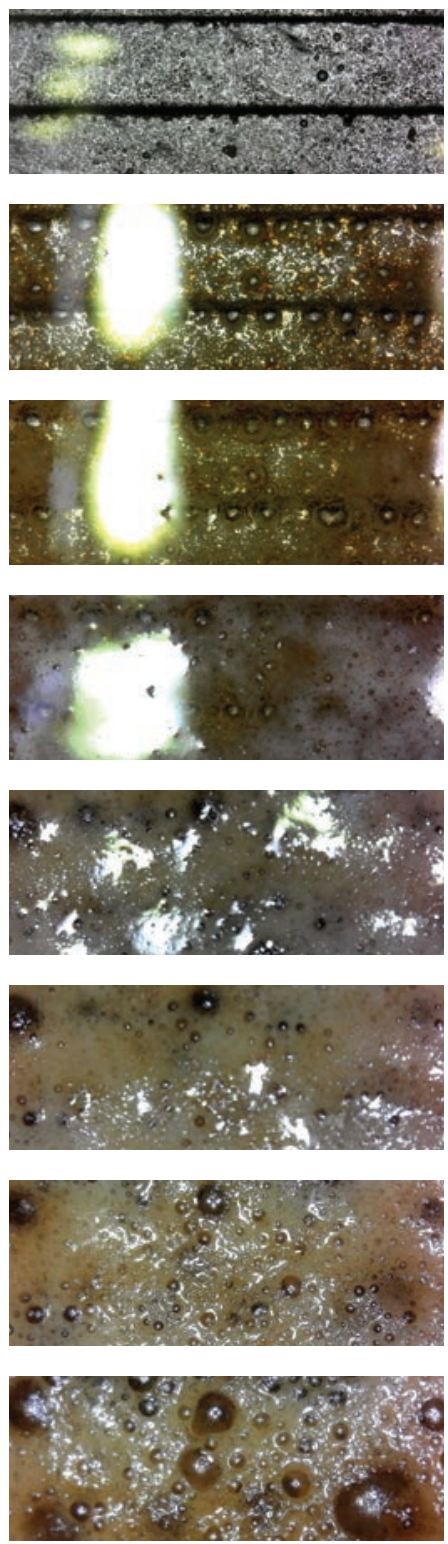
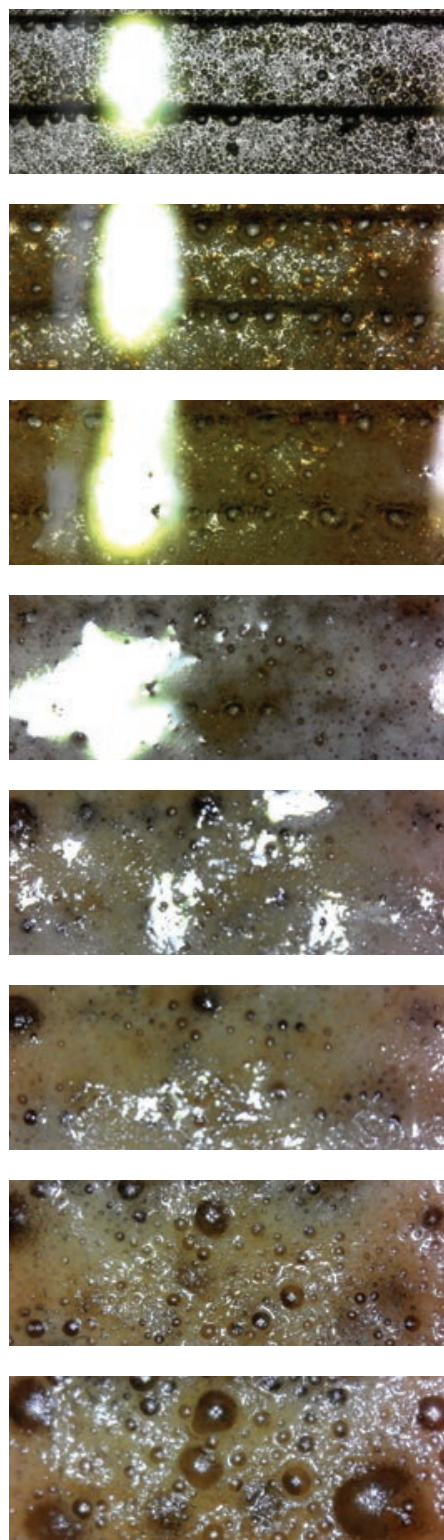
a second time, and again the solution was allowed to evaporate.

OBSERVATIONS: The effects of the oxidation accelerator solution were much more immediate than initially expected. Upon contact with the steel, the solution immediately began to show signs of oxidation-through the clear liquid, it was possible to observe with the steel turning orange as the iron oxide began to form. After 10 minutes, the solution could be seen frothing and bubbling, and exhibiting a bright orange colour. In the preliminary experiments for this test, the oxidation accelerator solution was tested on steel wire, and although the effects on the wire were visible, the reaction was much less significant than the results of this test. 


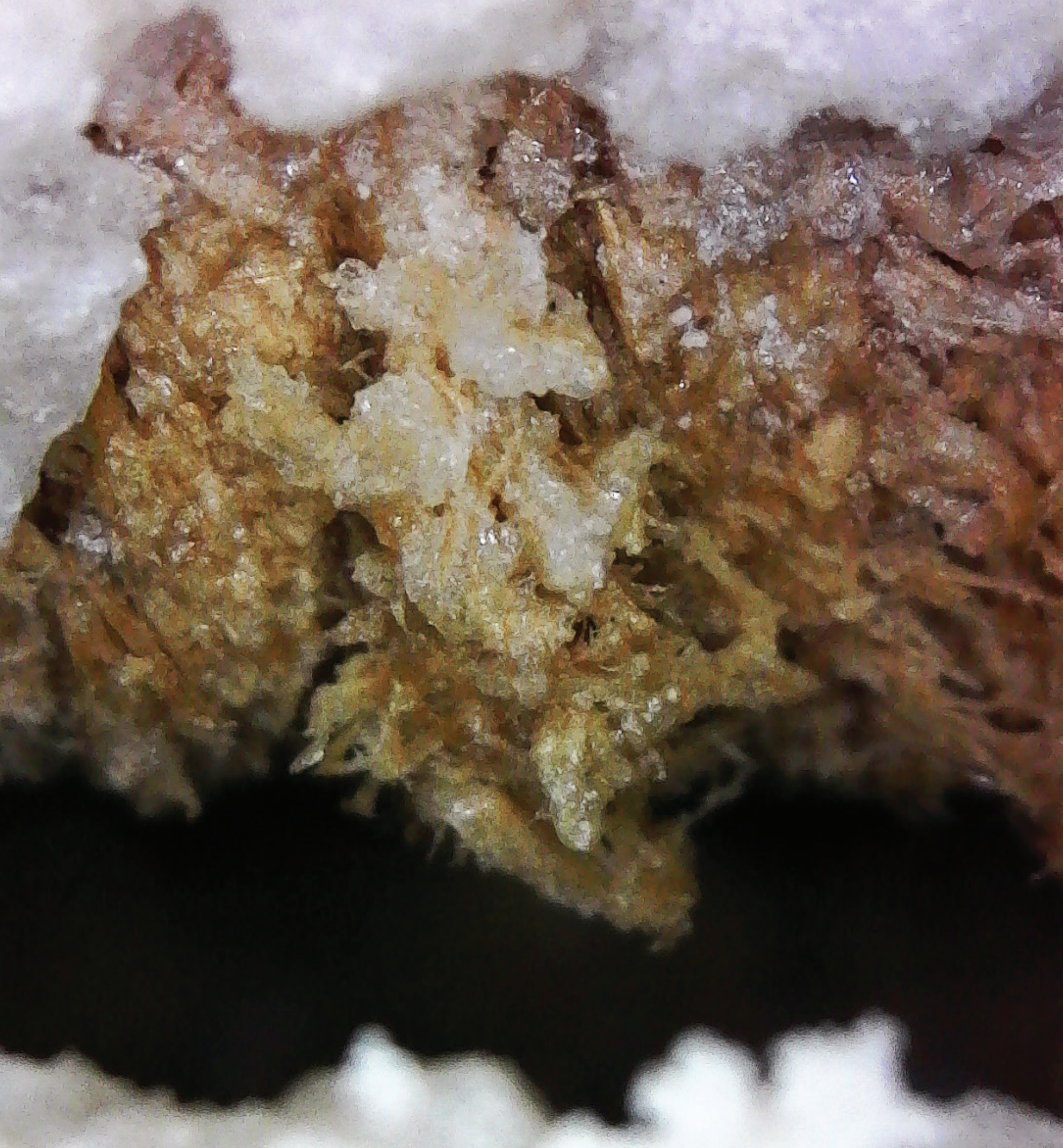

Efflorescence of wood at conclusion 


\section{WOOD TEST NO. 1}

EFFLORESCENCE

BACKGROUND RESEARCH: Many species of wood, and softwoods in particular, are prone to soaking up moisture due to the straw-like structure of the cells wood is made from. This can cause any number of problems for wood that hasn't been sealed or treated, including swelling and rotting. Even wood that has been treated to prevent moisture absorption will eventually succumb to these kinds of problems, as the natural tendencies of the material ultimately win out. This test examined the effects of wood that soaks up salt water-a significant problem for wood exposed during the Ontario winter, as salt is widely (and liberally) used as a de-icer.

As mentioned previously in Concrete test \#1, salt can be particularly harmful, not only as it blooms on the surface, but also as it forms inside the structures of the wood and can cause checking and cracking. Although the material used in this test was cedar, which is naturally quite rot-resistant, the desire was to demonstrate that even the most decay-resistant species of wood commonly used in Canada is still not immune to the damaging effects of the environment. The effects on other species of woods would likely be much worse.

HYPOTHESIS: Similarly to the concrete test \#1, the hypothesis for this experiment is that salt will bloom on the surface of the wood after partial immersion in solution. As in previous tests, full immersion will not be necessary to see growth, as the wood will soak the salinated water in through the cells. 
METHods: Cedar wood was used for this test, as it is a very soft wood with wide pores (and for the demonstration effects mentioned above). The model was cut using CNC router (computer numerical control) from a single piece of dried, non-treated cedar. A saturated salt solution was made using three parts distilled water to one part iodized table salt, stirring over high heat for 10 minutes, and allowed to cool. The model was placed in a sterile petri dish, and one tablespoon of room temperature (approx. 20 degreesC) saturated salt solution was added. The model was then left uncovered in the petri dish for 24 hours. After 24 hours, the model was photographed. Another 1 tablespoon of room temperature solution was added to the petri dish with the model, and allowed to evaporate again. This process of checking after 24 hours, photographing, then adding more salt solution was completed a total of four times. After the wood, like the concrete in Concrete test \#1, had achieved significant salt growth, the experiment was paused.

OBSERVATIONS: This test was completed after Concrete test \#1, so there was some framework for what to expect in terms of growth. That said, the growth patterns on the wood occurred at a more rapid rate than the concrete, and also travelled farther up the model, even though the same amount of liquid was added to the petri dish. The majority of the salt crystals on the wood model were formed at the very top, compared to the line of crystal growth on the concrete model. 


\section{WOOD TEST NO. 2 \\ TEMPERATURE/WATER DAMAGE}

BACKGROUND RESEARCH: While cedar is a common material in construction, it is not generally used to support heavy loads, as it is not as strong as other lumber options. Cedar is usually only seen in a decorative capacity, such as shingles, deck wood, trim, or siding on houses. Because the wood is so soft, it can be very prone to physical damage such as scratches and denting from blunt forces.

Cedar (along with many other species of woods) is also prone to damage due to changes in water content. More specifically, what happens with that content changes rapidly due to temperature fluctuations. When the moisture content of a piece of wood is rapidly decreased, the wood can check or split, opening it up to more decay and shortening its lifespan.

HyPOTHESIS: The goal of this experiment is to try and get the model to check, or split from a rapid change in moisture content. It's predicted that the model will show signs of splitting quickly (10-15 minutes) once submitted to the drying process.

METHODS: The model was cut using a CNC router (computer numerical control) from a single piece of dried, non-treated cedar. The model was then allowed to soak in water for 24 hours to get the moisture content of the wood as high as reasonably possible. The model was then taken from the bath of water and placed under heat at $200^{\circ} \mathrm{F}$, and set for 1 hour. 
ObSERVATIONS: Upon taking the model out of the heat, as soon as the model was picked up, it was so brittle from being dried that it split right down the middle. When the two pieces fell onto the table, two more pieces of the model broke off. The feel of the wood was drastically different from when it started: the model began with the soft, almost squishy feeling of normal cedar, but after the drying process, the model felt brittle and delicate. 


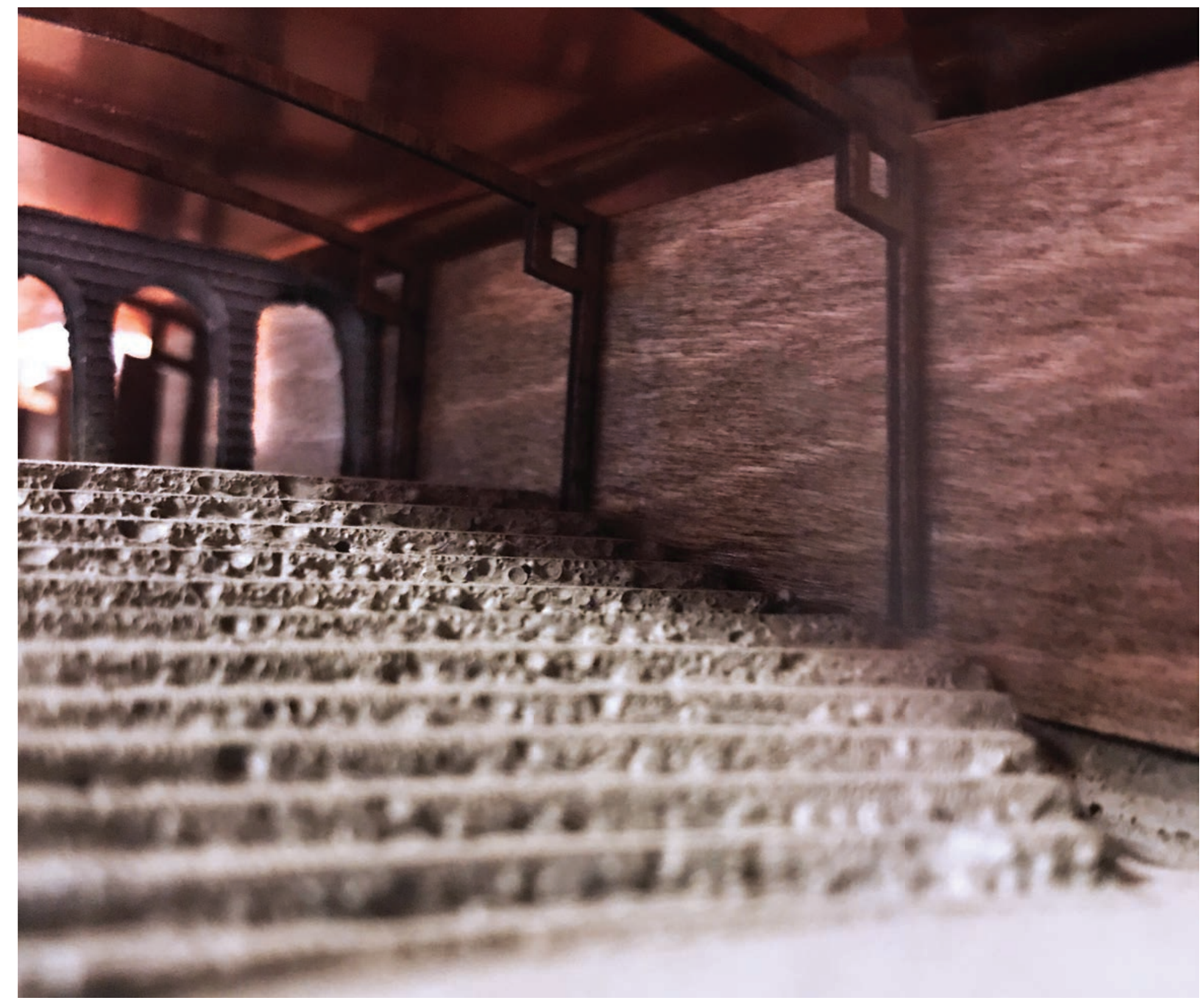




\section{PART 3: A THEATRE IN TIME}

MODEL 1: THE OPENING ACT

\section{NEPEAN POINT REVITALIZATION AHEAD}

By Stella Burgess

The managers of the Local Made-up Theatre Company (LMTC) have put out a call for a custom designed transitional theatre space, while their permanent space undergoes major renovations. The LMTC's current theatre has been in need of a major overhaul for many years, but the company cannot afford to close down while renovations are under way, hence the plan for a temporary theatre space to be vacated after the two-year renovations are complete.

The theatre specifications call for seating for 300 , transition and circulation spaces, an outdoor/indoor eating area, a ticket office, public washrooms, and back space for a sets workshop and performer change rooms.

"LMTC has an exciting future ahead, and to meet that future we know we need a physical space that is creative yet functional, just like our performances," said LMTC General Manager, Jane Smith. "Our current space has served us well over the past quarter-century. Now we're preparing to embrace the next." 


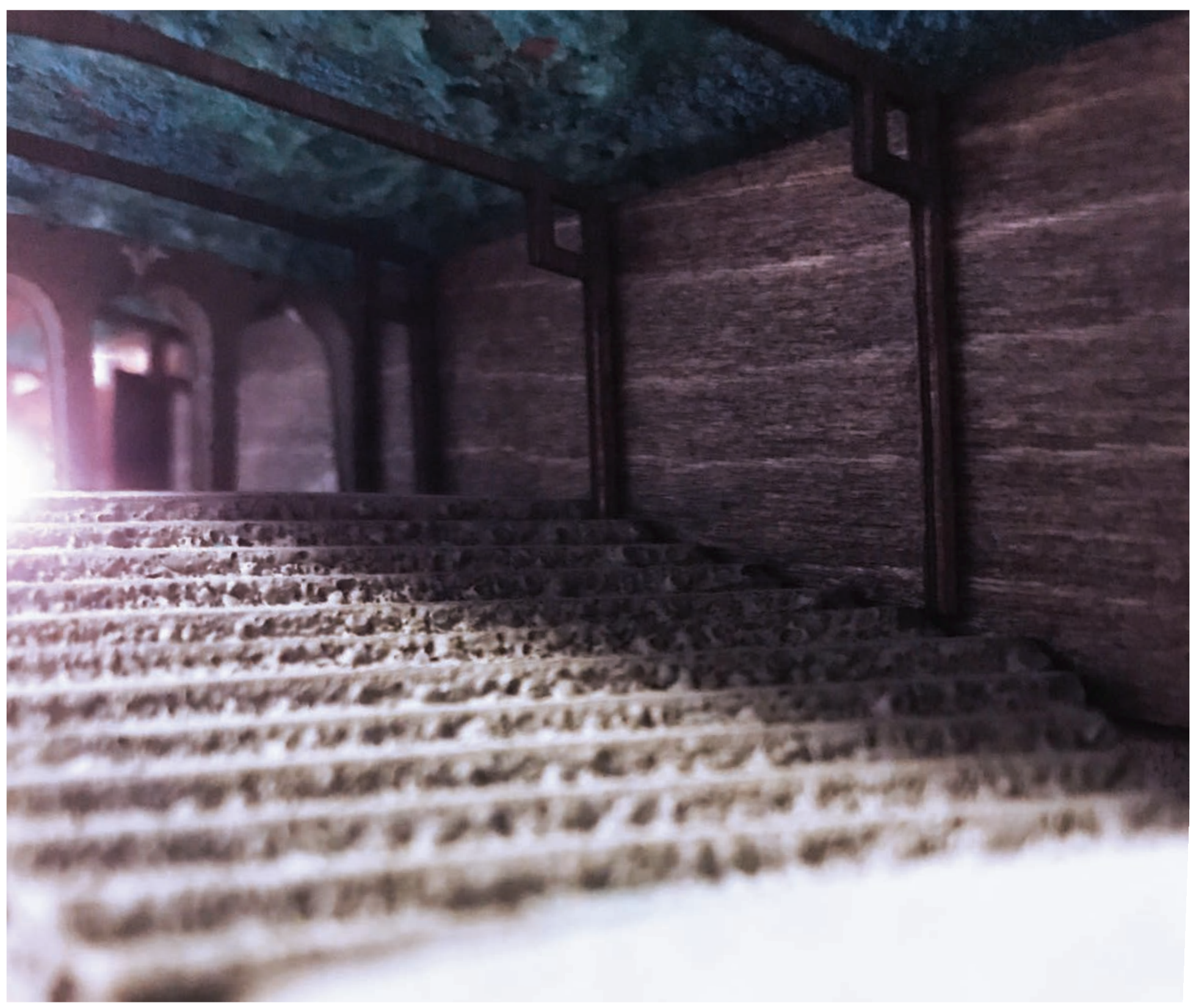




\section{LMTC SHUTS DOORS AT NEPEAN POINT THEATRE}

By RALPH GREGOR

After a successful 5-year occupation, the directors at the Local Made-Up Theatre Company have announced their plans to shut the doors at the Nepean Point Amphitheatre. The building, originally intended to be occupied for 2 years while the LMTC did major renovations on their permanent location, became such a popular destination that the company extended their stay 3 years past the intended move-out date. "The plan was never to permanently occupy this site," said LMTC General Manager, Jane Smith. "The time has come for the LMTC to step aside, and allow another occupation of the site to take our place. While we loved our time at Nepean Point, we look forward to seeing what comes next."

The NCC has announced that they plan to host a student competition to design the next iteration for the Nepean Point Amphitheatre, once the Local Made-up Theatre Company has completed their move back to their permanent location. 


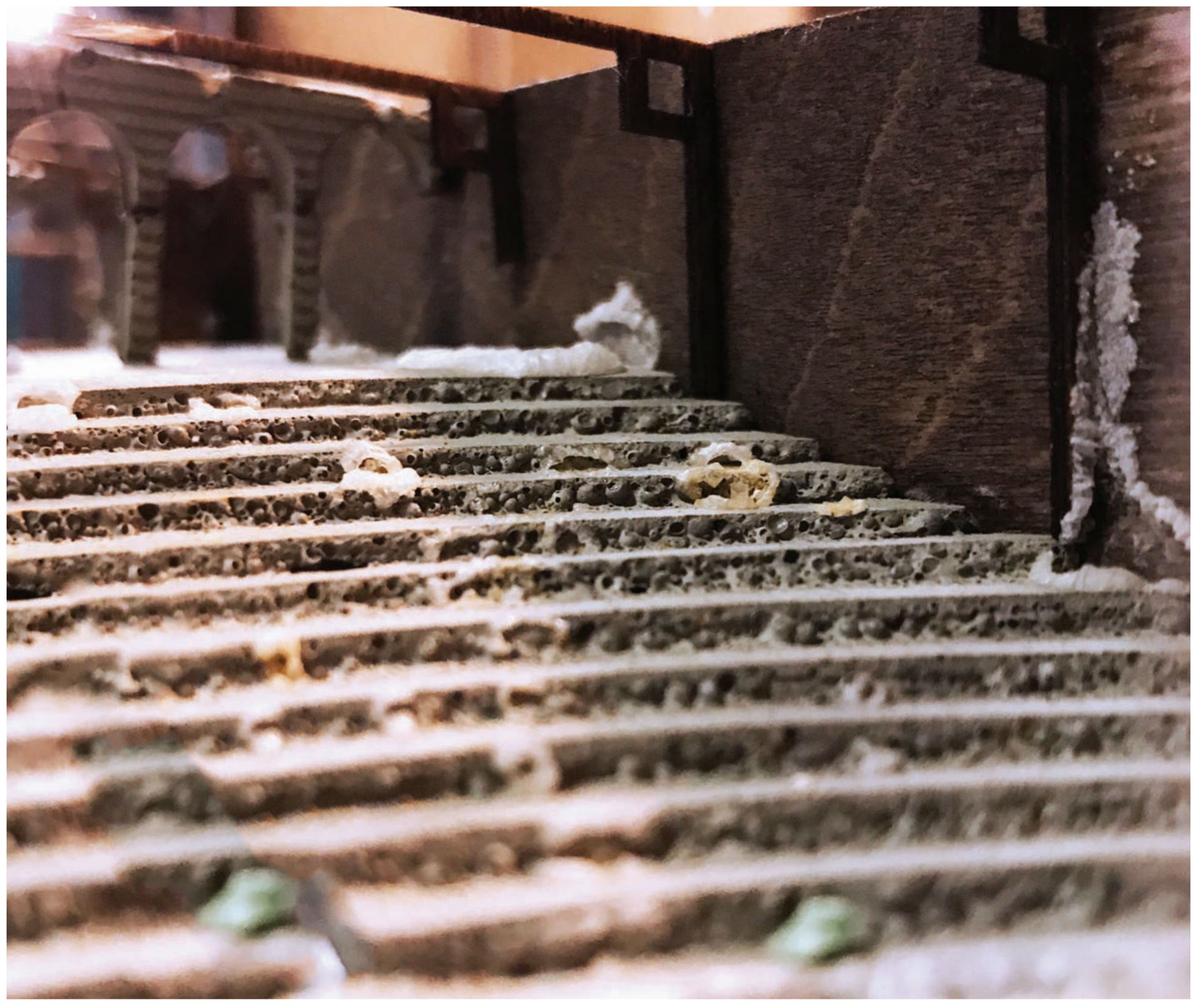




\section{NEPEAN POINT DESIGN COMPETITION}

By Francis McFarlane Nearly 70 students from Carleton University's Azrieli School of Architecture and Urbanism are taking part in a competition this spring to

I am a part of all that I have met;

Yet all experience is an arch wherethro'

Gleams that untravell'd world whose margin fades

Forever and forever when I

move.

How dull it is to pause, to make an end,

To rust unburnish'd, not to shine in use!

LEFT: Model \#3 photograph (photo by author)
-Ulysses, Alfred Lord

Tennyson, 1833 redesign the Nepean Point Amphitheatre. The Local Made-Up Theatre Company had previously occupied the space during the renovations to their permanent location. With their renovations complete, the LMTC has vacated the Amphitheatre, and the site stands open and waiting for redevelopment.

The Nepean Point Amphitheatre Competition, sponsored by the National Capital Commission, and working in conjunction with the City of Ottawa, is designed to tap into ideas generated by the 70 graduate and undergraduate architecture students as part of the competition. "The effort is part of a larger revitalization initiative that began when the Local
Made-Up Theatre Company approached the NCC for assistance in improving the area, and creating a lasting creative space on the site," said Helen Jones, competition coordinator.

The plan is to have the students come up with proposals to transform the currently vacant site at Nepean Point using recycled materials from the previous building into a "highly visible and active public space, aimed at gathering and sharing stories," according to the proposal. The competition will close on May 10th, after which the winning projects will be announced, and plans for construction will commence. 


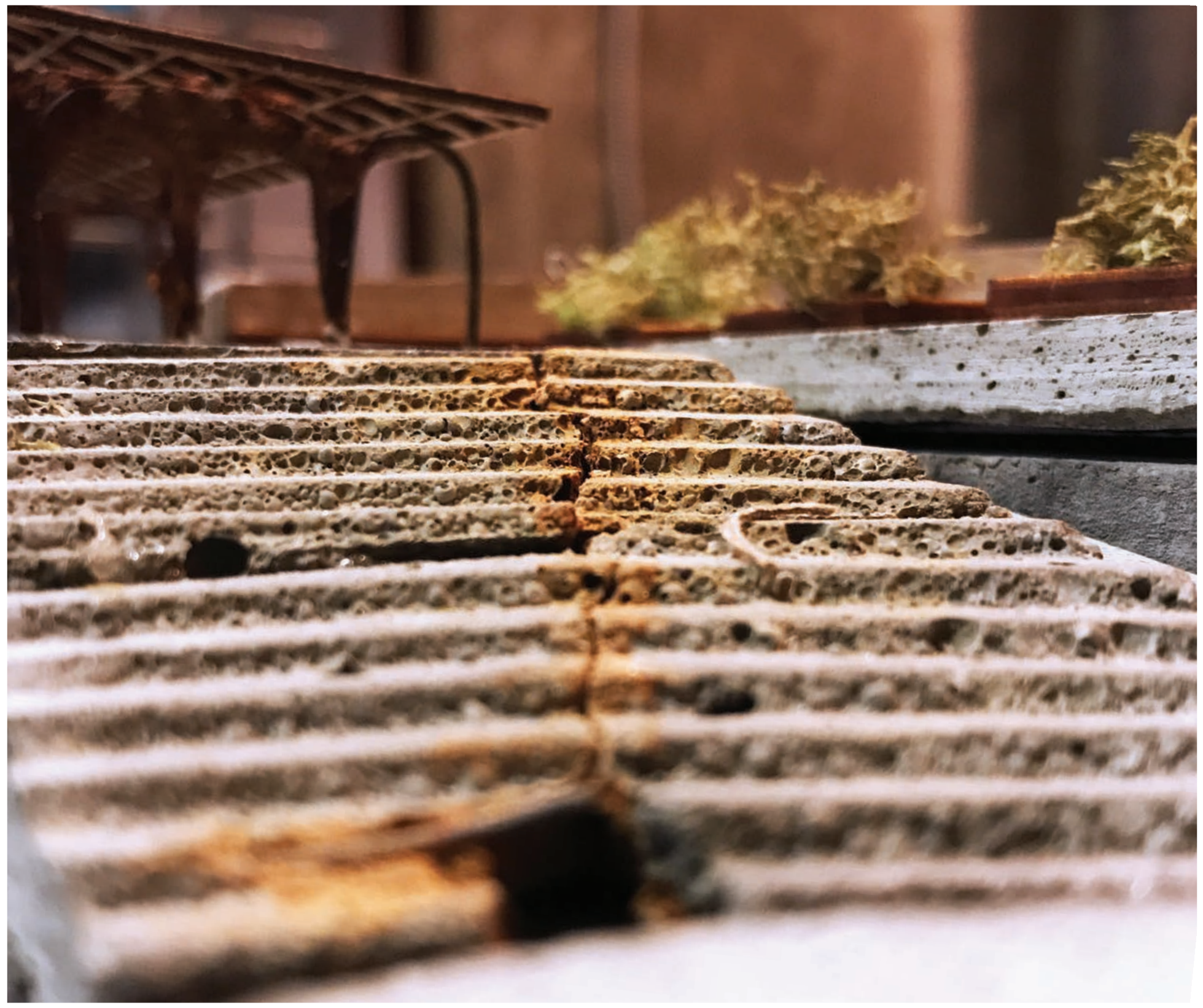




\section{CONSTRUCTION BEGINNING AT NEPEAN POINT}

BY SALLY KIRK

Construction on the winning project of the Nepean Point Amphitheatre Competition will begin this week. Announced in February, and launching this fall, the latest project at the Nepean Point Amphitheatre will transform the recently vacated lot into a community open-air theatre space and café. The café will feature a cultural arts gallery with rotating displays of sculptures, murals, woven arts, and musical performances.

"We look forward to the renewed and expanded use of the Nepean Point Amphitheatre," said Jim Jones, spokesperson for the NCC. "The public has shown great interest in this phase of the ongoing transformation of the area, and we've heard nothing but excitement at this next iteration." 


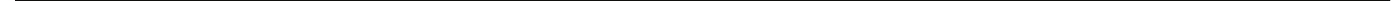




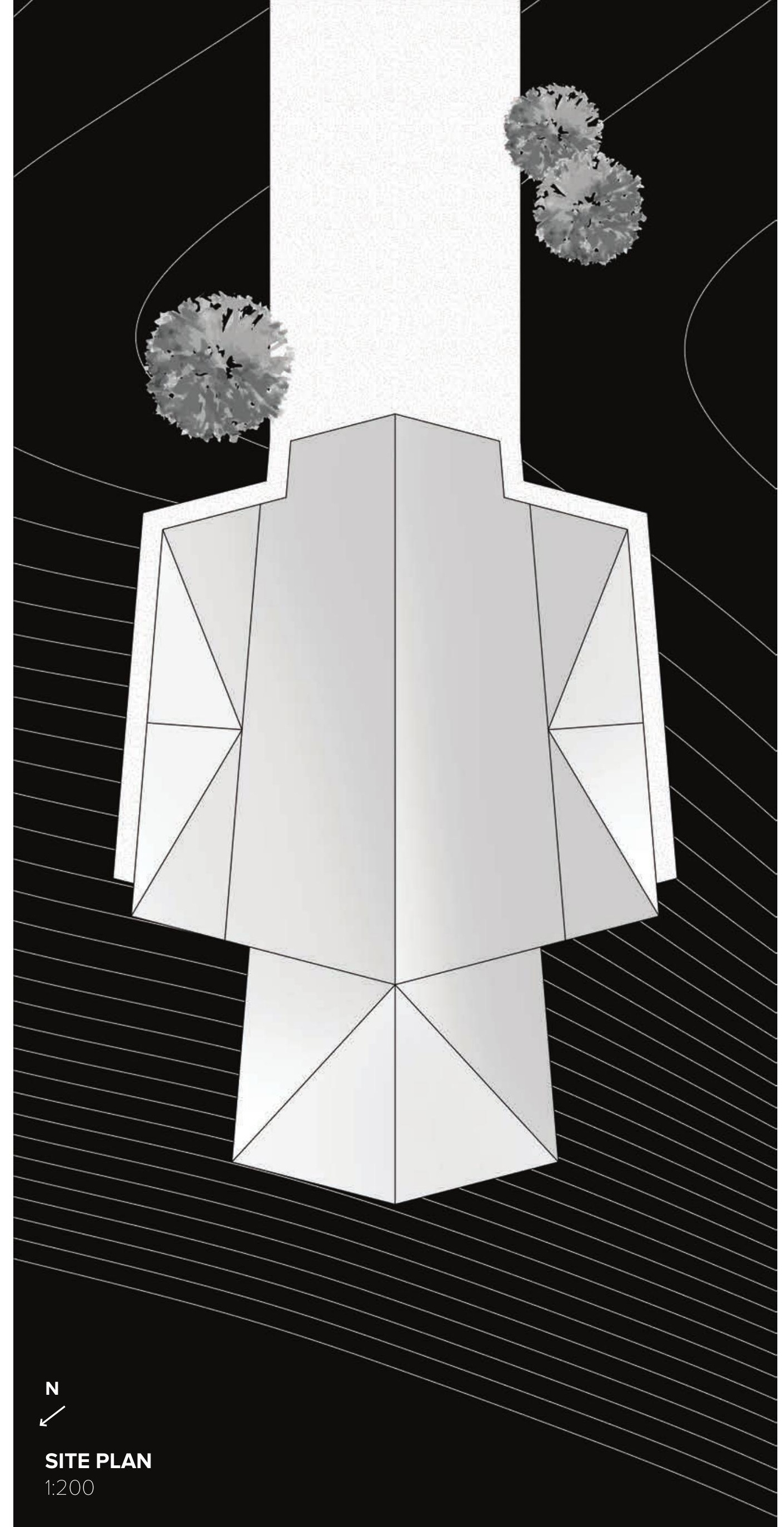



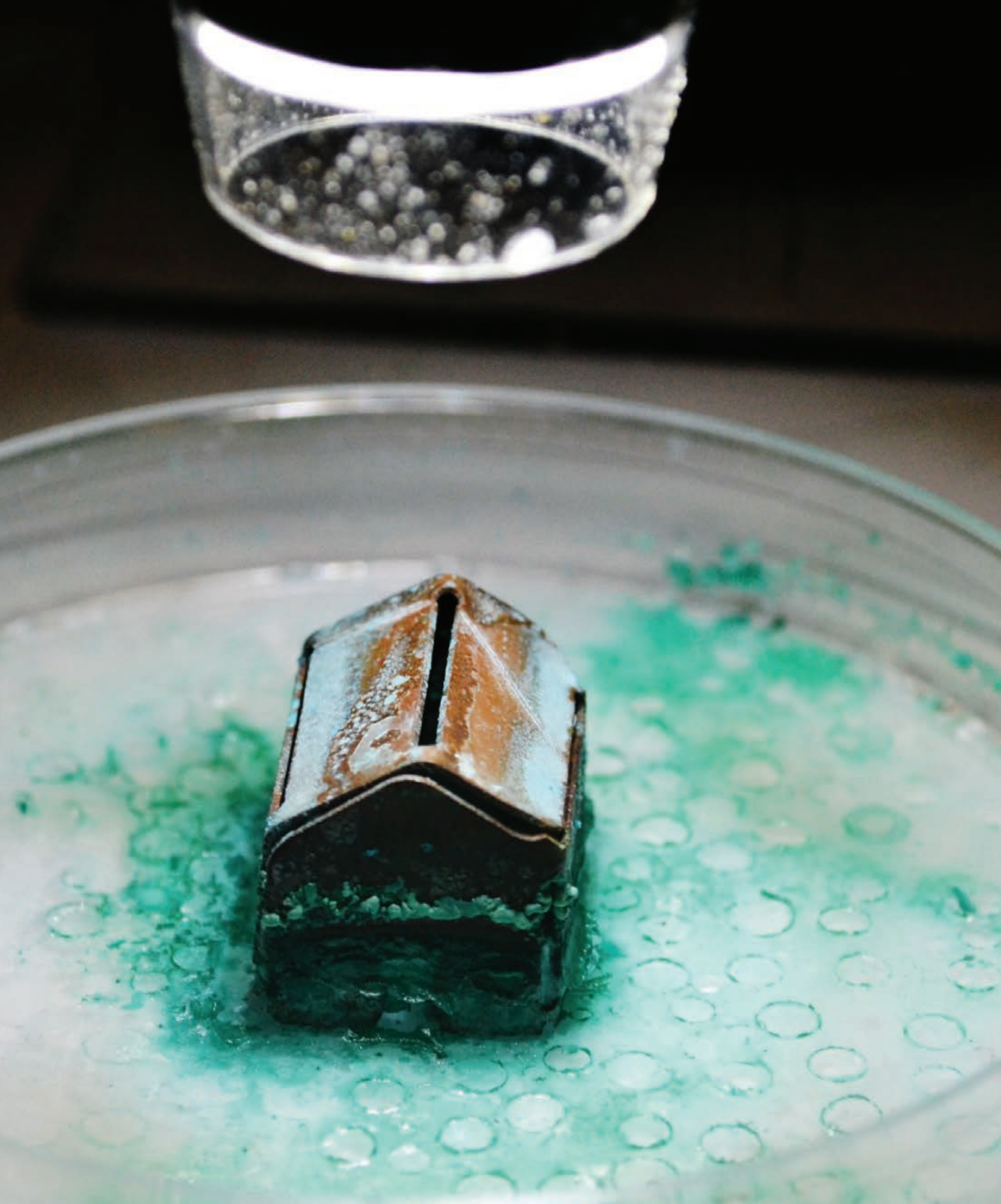


\section{POSTSCRIPT}

Canada's built history extends back only a few hundred years, in contrast to that of Europe, where some buildings go back to the Greco-Roman era, or Egypt, with its 4,500-year-old Giza pyramids. By contrast, while Canada's history extends back thousands of years, and First Nations peoples lived in well-established communities, the nature of much of their built environment was temporary and often intended to be torn down, packed up, and moved from site to site. These temporary structures were in no way shoddy or poorly built, but reflected the needs of the communities they served.

No building, no matter where it is situated, is truly "permanent": all built structures will weather and change over time. In this project, the goal has been to experiment with temporality, to create an architecture that doesn't rely on monumental, iconic fixtures in the built environment. The design of the Nepean Point amphitheatre project relies more on the idea of being in the moment, of capturing and appreciating fleeting, ephemeral experiences that can never be replicated-as when one watches the performance of a play.

The purpose of this thesis is by no means to change the way we practice architecture-people still need buildings that last, and we, as architects still need to try our very best to fight the degenerative process. However, as a thought experiment, this thesis is intended to explore the possibilities inherent in embracing and utilizing degeneration as a positive force in the built environment.

experiments (photo by author) 


\section{BIBLIOGRAPHY}

"[TRANS-]ient." [TRANS-] Journal, no. 3 (2017).

Allen, Edward, and Joseph lano. Fundamentals of Building Construction. 6th

Edition. Wiley, 2014.

Belmond, Cecil. informal. Prestel, 2001.

Benner-Nawman, Inc. BN Inc. 2017. http://www.bnproducts.com/blog/whatare-the-different-types-of-rebar-and-why-do-types-matter/.

BlingCrete. Transmaterial. November 18, 2018. http://transmaterial.net/ dyscrete/.

Carleton University. "Ottawa 1:2,500 Scale Topographic Maps." 1971. http:// carleton-u.maps.arcgis.com (accessed January 2019).

DuPlessis, C., and B. Edwards. "Global Perspectives: Learning from the other side." Architectural Design, no. 152 (2001): 38-45.

Ecovative Design. Transmaterial. May 5, 2011. http://transmaterial.net/ mycobond/.

Juniper, Andrew. Wabi Sabi: The Japanese Art of Impermanence. Tuttle Publishing, 2003.

Merrian Webster Dictionary. www.merriam-webster.com (accessed November 16, 2018).

Mostafavi, Mohsen, and David Leatherbarrow. On Weathering. London: The MIT Press, 1993.

Myers, William. Bio Design. New York: MoMA, 2012. 
Pafumi, G. R. Is Our Vision of God Obsolete?: Often What We Believe Is Not What We Observe. Xlibris Corporation, 2015.

Ralls, Kenneth M., Thomas H. Courtney, and John Wulff. Introduction to Material Science and Engineering. John Wiley \& Sons, 1976.

Rice, Peter. An Engineer Imagines. Batsford, 1994.

Skiena, Steven. The Algorithm Design Manual . 2nd Edition. Springer, 2008.

Tennyson, Alfred Lord. Ulysses. Vol. 1, in Poems. London, 1842.

The National Capital Commission. Nepean Point. 2018. http://ncc-ccn.gc.ca/ places/nepean-point.

The RAND Corporation. A Million Random Digits with 100,000 Normal Deviates. The Free Press, 1955.

Vincent, Julian, Olga A Bogatyreva, Nikolaj R Bogatyrev, Adrian Bowyer, and Anja-Karina Pahlis. "Biomimetics: its practice and theory." 2006.

Weisman, Alan. The World Without Us. Harper Collins Publishing, 2007.

Wikipedia. Deterministic algorithm. 2018. https://en.wikipedia.org/wiki/ Deterministic_algorithm.

-. Heuristic (computer science). 2018. https://en.wikipedia.org/wiki/ Heuristic_(computer_science).

-. Theory of Everything. 2018. https://en.wikipedia.org/wiki/Theory_of_ everything. 